\title{
Secrets and Lies: A Profile-Based Examination of Youth and Parent Information Management Strategies and Adolescent Electronic Cigarette Use
}

Desiree N. Williford

Follow this and additional works at: https://researchrepository.wvu.edu/etd

\section{Recommended Citation}

Williford, Desiree N., "Secrets and Lies: A Profile-Based Examination of Youth and Parent Information Management Strategies and Adolescent Electronic Cigarette Use" (2017). Graduate Theses, Dissertations, and Problem Reports. 6958.

https://researchrepository.wvu.edu/etd/6958

This Thesis is protected by copyright and/or related rights. It has been brought to you by the The Research Repository @ WVU with permission from the rights-holder(s). You are free to use this Thesis in any way that is permitted by the copyright and related rights legislation that applies to your use. For other uses you must obtain permission from the rights-holder(s) directly, unless additional rights are indicated by a Creative Commons license in the record and/ or on the work itself. This Thesis has been accepted for inclusion in WVU Graduate Theses, Dissertations, and Problem Reports collection by an authorized administrator of The Research Repository @ WVU. For more information, please contact researchrepository@mail.wvu.edu. 
Secrets and Lies: A Profile-Based Examination of Youth and Parent Information Management Strategies and Adolescent Electronic Cigarette Use

Desireé N. Williford, B.S.

Thesis submitted to The Eberly College of Arts and Sciences at West Virginia University

in partial fulfillment of the requirements

for the degree of

Master of Science

in

Psychology

Christina L. Duncan, Ph.D., Chair

Aaron Metzger, Ph.D.

Cheryl McNeil, Ph.D.

Department of Psychology

Morgantown, West Virginia

2017

Keywords: electronic cigarettes, adolescent, parent, information management strategies

Copyright 2017 Desireé N. Williford 


\begin{abstract}
Secrets and Lies: A Profile-Based Examination of Youth and Parent Information Management Strategies and Adolescent Electronic Cigarette Use
\end{abstract}

Desireé N. Williford, B.S.

Introduction: The use of electronic cigarettes is growing among adolescents residing in the United States, tripling in prevalence over the past few years. Yet, electronic cigarettes are relatively new and there is limited research on parent and youth behavior and information management strategies as they relate to adolescent use of electronic cigarettes. Objective: The current study had a primary goal of utilizing a profile-based analytic procedure (cluster analysis) to explore patterns among these variables and investigate relations to adolescent use of electronic cigarettes. Method: A total of 562 high school students between the ages of 13 and 18 years (M age $=15.95, \mathrm{SD}=1.16$ ) were recruited from four high schools across West Virginia, Pennsylvania, and Ohio, and an adolescent medicine clinic in West Virginia. Students completed a packet of questionnaires in the clinic or school setting. Hierarchical and k-means cluster analyses, chi-squares with post-hoc testing, ANOVA, and MANOVA procedures were used to assess primary aims. Results: The majority of the sample (56.8\%) indicated no lifetime use of electronic cigarettes. However, rates of electronic cigarette use (16.7\%) and dual cigarette use $(22.2 \%)$ were consistent with the current literature. Demographic differences emerged between user groups, particularly for grade classification, family status, and parental education level. Cluster analysis results suggested a two-cluster solution, mainly distinguished by levels of adolescent secrecy. A "secretive" cluster indicated high youth secrecy, and moderately low levels of youth disclosure, parental behavioral control, parental knowledge, and parental solicitation; a "less secretive" cluster indicated inverse findings. User group was also 


\section{PROFILES OF YOUTH AND PARENT INFORMATION MANAGEMENT}

significantly related to cluster profile, such that more never users $(78 \%)$ were found to be in the "less secretive" cluster as compared to electronic cigarette users $(11.8 \%)$ and dual users $(10.2 \%)$.

In all, results suggest the potential of bidirectional associations between parental and youth behavioral and information management strategies as well as differences in profiles for electronic cigarette and dual users as compared to non-users. These findings have the potential of spurring future research on specific parent and adolescent information strategy usage as clarify the 2015 Surgeon General's Call of Action, particularly in regards to eliciting parent help in reducing electronic cigarette use among adolescents. Results also have the potential to inform youth-focused education and preventative efforts. 


\section{Acknowledgments}

I would like to thank my primary research advisor and thesis committee chair, Dr. Christina Duncan, for her guidance and support throughout this project. I am grateful for her belief in me, as this project involved a great deal of learning and growing, particularly in regard to statistical analyses. I am also very happy to take this opportunity to thank my committee members, Drs. Aaron Metzger and Cheryl McNeil, for their valuable feedback throughout every stage of this project. Their dedication and drive to help me develop the best possible thesis project truly aided my understanding of the research process and taught me valuable lessons about the power of mentorship.

I would also like to thank the current members of the Pediatric Lab for Adherence and Transition at West Virginia University, including Paul Enlow, Ellen Manegold, Lisa Hynes, Kristine Durkin, and our large group of undergraduate students. Each of these individuals greatly assisted in making this project possible and a resounding success. Data entry and recruitment truly would not have been possible without their incredible effort and time commitment. I also would particularly like to thank Paul Enlow for allowing me to build my project off of his dissertation project.

Finally, I would like to take a moment to thank the teachers and Adolescent Clinic staff for their support of my project and allowing me to recruit from their population. I would also especially like to thank the adolescent participants for providing me with a wealth of information as well as their parents for providing consent for the youth to participate. I am also truly grateful to my family and friends for their plethora of love, support, encouragement, and guidance throughout this entire process. 
Table of Contents

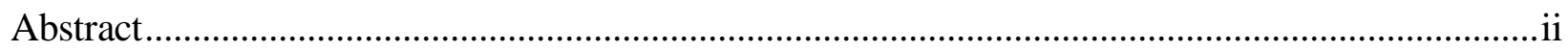

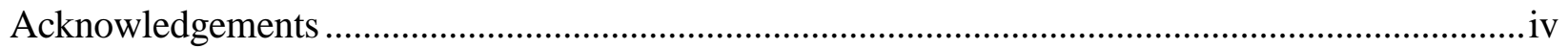

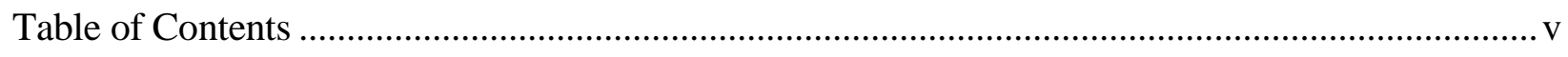

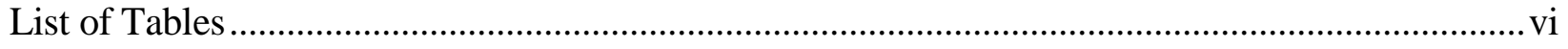

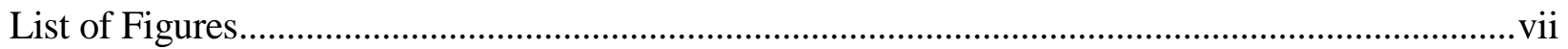

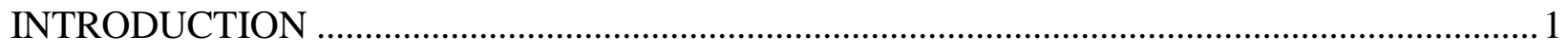

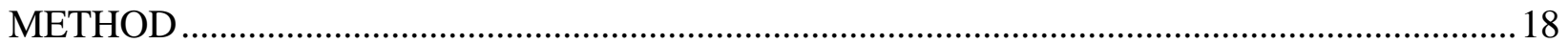

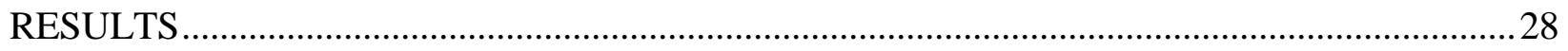

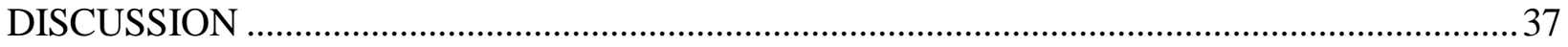

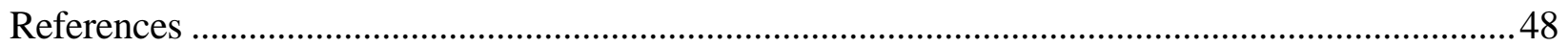




\section{List of Tables}

Table 1: Coding of Variables Used in Analyses ..........................................................................5

Table 2: Participant Demographics and Frequencies ..................................................................58

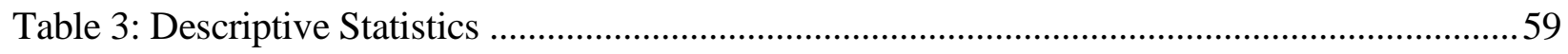

Table 4: Skew and Kurtosis Information for Outcome Variables ..................................................6 60

Table 5: Current Use of Electronic Cigarettes among E-Cigarette Only Users and Dual User .......61

Table 6: Games-Howell Post-Hoc Analyses for Aim 1 ...........................................................62

Table 6 Continued: Games-Howell Post-Hoc Analyses for Aim 1 ............................................63 


\section{List of Figures}

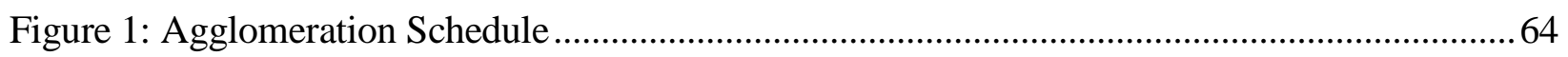

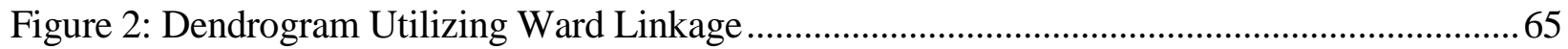

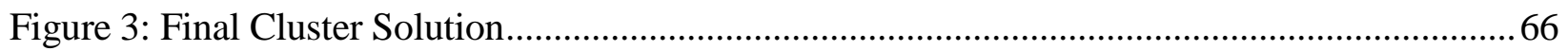


Secrets and Lies: A Profile-Based Examination of Youth and Parent Information Management Strategies and Adolescent Electronic Cigarette Use

It is not a new phenomenon that adolescents and adults are using tobacco products. In fact, according to the Centers for Disease Control (CDC) and Prevention (2015a), smoking remains the leading cause of preventable death, resulting in nearly 6 million deaths annually. Despite the high mortality rate and large public knowledge regarding the negative effects of smoking, thousands of individuals under the age of 18 begin smoking behaviors. In particular, within the United States, it is estimated that each day over 3,000 youth try a cigarette for the first time and an additional 2,100 youth and young adults initiate daily smoking habits (CDC, 2015a). Given these statistics, research and clinical practice has focused a great deal of energy on the creation, implementation, and dissemination of smoking prevention and cessation programs more generally, with some success with adolescent populations (e.g., DiClemente, Hansen, \& Ponton, 2013; Jensen et al., 2011). Traditionally, preventative education strategies at the school and governmental levels have been an area of focus (CDC, 1994; DiClemente, Hansen, \& Ponton, 2013); however, more recently, the CDC has called for action by parents, teachers, healthcare providers, and others to become more involved in advising youth about the potential dangers of smoking behaviors, including the use of electronic cigarettes (DHHS, 2016).

\section{A New Alternative to Traditional Smoking}

In the past 20 years, there has been a notable decline in conventional cigarette smoking by adolescents in the United States (CDC, 2010). Simultaneously, however, new alternatives to conventional cigarette smoking have increased, thereby negating such progress (CDC, 2015a; Perrin, 2014). One such alternative, which is the focus of the current paper, is Electronic Nicotine Delivery Systems (ENDS), more commonly referred to as electronic cigarettes (or e- 
cigarettes, e-cigs, vapor products). First created in 2003, electronic cigarettes were originally designed as an alternative method of nicotine delivery that did not require combustion and released a toxin-free vapor (Bertholon, Becquemin, Annesi-Maesano, \& Dautenzberg, 2013; Goniewicz, Kuma, Gawron, Knysak, Kosmider, 2013). Each device consists of 3 basic parts: (1) a cartridge to hold the e-liquid; (2) a heating element, or vaporizer; and (3), a battery, often rechargeable (Moreno, 2014). To use an electronic cigarette, the user takes a puff, similar to the use of a conventional cigarette, which then activates the vaporizer. The heat from the device then turns the e-liquid into aerosol, which is inhaled by the user. The use of electronic cigarettes has been termed "vaping" by the general public (Brown \& Cheng, 2014; Moreno, 2014).

As previously alluded to, electronic cigarettes have significantly different appearances and functions today in comparison to older variations. While original electronic cigarettes resembled conventional cigarettes, known as "cigalikes," they have increased in size (i.e., around the size of a pen) and have become more distinct and sophisticated in appearance, modifiability, and capabilities (Zhu et al., 2014). In today's consumer environment, it is estimated that there are more than 460 different brands of electronic cigarettes available, ranging in cost (e.g., \$6 for disposables to $\$ 65$ for starter packs), with a wide variety sold in the United States (Zhu et al., 2014). Additionally, given advances in technology and the impact through the Internet and social media, advertising and information regarding electronic cigarettes has been disseminated widely, contributing to their popularity. This is evidenced by the large percentage of electronic cigarette sales conducted online (i.e., approximately 30-50\% of all electronic cigarettes sales; Zhu et al., 2014). Key marketing strategies of electronic cigarette companies and their highly unregulated nature has also contributed to their rise in popularity, particularly given that these companies have freely described the product as safer and healthier than conventional cigarettes, often with 
little supporting evidence (de Andrade, Hastings, \& Angus, 2013; Zhu et al., 2014). As such, many consumers, including adolescents, interpret these messages as truth, which is concerning given the recent trend in increased exposure to electronic cigarette advertisements among youth

(Duke et al., 2014).

\section{Health Consequences of Electronic Cigarettes}

The FDA has reported that evidence does not support the claimed health benefits of electronic cigarette use in comparison to traditional cigarette use (Palazzolo, 2013). Rather, research has shown early evidence indicative of the possibility of adverse health effects related to prolonged use of electronic cigarettes (Palazzolo, 2013). An initial concern is the levels of toxins found within an electronic cigarette's e-liquid solution. While the solution is typically made up of relatively harmless substances (propylene glycol [PG], glycerol), chronic exposure to these substances (and to the cartridges that hold them) has been associated with negative symptoms, such as those pertaining to respiratory symptomology, eczema, allergic reactions, eye irritation, dry mouth, and dry throat (Grana, Benowitz, \& Glantz, 2014; Hajek, Etter, Benowitz, Eissenberg, \& McRobbie, 2014).

Furthermore, there has been concern regarding changes that occur when electronic cigarette ingredients are heated to a high temperature within the device (Grana, Benowitz, \& Glantz, 2014; Hajek, et al., 2014; National Institutes of Health, 2010; 2012). For example, the FDA and other researchers have found toxic solvents, heavy metals, and carcinogenic compounds when testing the aerosol of electronic cigarettes (Grana, Benowitz, \& Glantz, 2014; Hajek, et al., 2014; Palazzolo, 2013; Rigotti, 2015; Williams, Villarreal, Bozhilov, Lin, \& Talbot, 2013). While potential moderate to severe health risks have been described in recent research (e.g., significant rises in blood pressure, changes in cardiovascular and respiratory 
function, burns due to cartridges exploding), these findings may lack generalizability given that these effects were reported in single case studies or very small samples and do not fully detail the extent (e.g., amount, frequency) of electronic cigarette usage (Grana, Benowitz, \& Glantz, 2014; Hajek, et al., 2014; Vardavas et al., 2012). Finally, the nicotine found in electronic cigarettes also poses a concern, particularly given its influence on brain development, potentially leading to deficits in impulse control, attention, and learning (e.g., CDC, 2015; Yuan, Cross, Loughlin, \& Leslie, 2015). Though highly controversial, some researchers (e.g., Dutra \& Glantz, 2014) have also found that using electronic cigarettes may contribute to nicotine addiction.

\section{Adolescent Use of Electronic Cigarettes, Appeal \& Perceived Benefits}

Even though it is illegal for youth to purchase electronic cigarettes (if under the age of 18 years), it is clear that adolescents are accessing and experimenting with them at an alarming rate. According to the CDC (2015), recent data from the 2015 National Youth Tobacco Survey (NYTS) has indicated further increase in prevalence estimates of "ever use" (i.e., at least one time) of electronic cigarettes, with $27 \%$ of youth between grades 6 and 12 indicating prior or current use. While data from the 2011 and 2012 NYTS indicated an increase from 4.7 to 10.0 percent in high school students, the 2015 prevalence rates were $37.7 \%$ in these youth, more than tripling the frequency (CDC, 2013; CDC, 2015).

In an attempt to better understand electronic cigarette use among adolescents, researchers have attempted to identify and describe the reasons for experimentation. For example, Kong, Morean, Cavallo, Camenga, and Krishnan-Sarin (2015) conducted 18 focus groups with middle school, high school, and college students to understand why these young people initiate and discontinue use of electronic cigarettes. The authors identified a number of themes related to experimentation, including (1) general curiosity, (2) flavor options, (3) family and/or peer 
influences, (4) easier access to the product, and (5) perceptions of electronic cigarettes as "cool" and a healthier or better option than conventional cigarettes. In this particular study, curiosity was shown to be the top reason for experimentation, followed by the appeal of multiple flavors and peer influences, suggesting that both flavors and social norms may a significant role in youth experimentation with electronic cigarettes (Kong et al., 2015).

Before truly effective prevention and intervention efforts can be crafted to address adolescent electronic cigarette use, more information and research is needed. In the interim, much information and guidance can be gleaned from a review of the larger literature base on tobacco use in adolescents in addition to current studies specific to electronic cigarette use. After all, recent studies have found that many youth who experiment with electronic cigarettes also experiment with conventional cigarettes. For example, it has been reported that $54.3 \%$ of ever users of conventional cigarettes reported ever use of electronic cigarettes and $80.6 \%$ of current conventional cigarette users (use in the past 30 days) reported current use of an electronic cigarette (CDC, 2015).

\section{Factors that Influence Adolescent Tobacco Use}

Numerous studies have shown that adolescence and young adulthood is a peak time for initiation of smoking behaviors (DHHS, 2012). Also, an individual is significantly less likely to begin smoking if they have not engaged in smoking behaviors prior to 26 years of age (DHHS, 2012), which highlights the importance of prevention. Given this knowledge, research on the risk and protective factors for adolescent smoking has been pivotal. While many risk factors have been identified on the individual, social, environmental, behavioral, and biological levels, for the purposes of this paper, a review of the literature regarding social influences will be emphasized; however, a brief overview of a few other factors will be noted. 
Sociodemographic factors. A number of sociodemographic factors, such as gender, race, ethnicity, socioeconomic status (SES), and developmental concerns, have been identified as related to adolescent use of both conventional and electronic cigarettes (DHHS, 2012). However, the research currently being conducted on electronic cigarettes has been somewhat mixed. While some recent research has suggested that using electronic cigarettes is disproportionately higher in Caucasian youth (e.g., Camenga et al., 2014), other studies have found that Hispanic and Hispanic-Caucasian students also were among the racial/ethnic groups reporting the highest use (CDC, 2015). Even more conversely, some studies (e.g., Suftin, McCoy, Morrel, Hoeppner, \& Wolfson, 2013) have suggested students of Hispanic and "Other" racial groups are more likely to report use of electronic cigarettes (at least once in their lifetime) as compared to Caucasian students. However, it is worth mentioning that this particular study used a young adult, collegeaged sample. Further, a recent study conducted in Hawaii found lower rates of electronic cigarette use among Caucasian adolescents in comparison to other racial/ethnic minority groups (Wills, Knight, Williams, Pagano, \& Sargent, 2015).

In addition to racial/ethnic factors, there is also evidence to suggest gender may play a role in predicting adolescent use of electronic cigarettes. A few studies have found that adolescent males have a higher propensity to report ever trying or using electronic cigarettes and other tobacco products (e.g., Dutra \& Glantz, 2014; Wills et al., 2015). Despite these findings, research on U.S. adolescent gender disparities for the use of electronic cigarettes is still quite limited and has not explored the interrelations between gender and other contributory risk and protective factors. As a result, additional, more thorough examinations of gender risk are essential. 
Finally, the environment in which an adolescent dwells (urban, suburban, or rural) may be associated with their use or non-use of electronic cigarettes. In past research with tobacco, for example, youth from rural environments (like the state of West Virginia) had higher rates of smoking behaviors (CDC, 2013; Owusu et al., 2016). While some research on adolescent use of electronic cigarettes has found contradictory results (i.e., urban living was a significant predictor) (e.g., Goniewicz \& Zielinska-Danch, 2012), most of these studies are based on international samples. As a result, it is not known how applicable or generalizable those results are to an American population, given cultural differences.

Social context. It has been well documented that adolescents are highly influenced by their social context, including their relationships with family members and peers. Peer influence has been documented across a number of adolescent problem behaviors, including tobacco use. Altered perceptions regarding the normalcy and social expectations of adolescent substance use as well as peer pressure to engage in these activities have been shown to be significant predictors of adolescent substance use (Liao, Huang, Huh, \& Pentz, 2013; Pants et al., 2015). Likewise, research has found that the transition from middle to high school is often viewed as a critical period for the influence of peers on adolescent risky behavior given the increasing interactions with friends and higher levels of independence (Liao et al., 2013).

Additional evidence in the electronic cigarette literature has shown support for the influence of family factors on product use by youth. One such study, conducted by Goniewicz and Zielinska-Danch (2012), found having a parent who smoked was a significant predictor of lifetime or current use of electronic cigarettes $(36.4 \%$ of youth between the ages of 15 to 24 years). Likewise, Pentz and colleagues (2015) found electronic cigarette use by youth to be significantly related to having a parent who owned an electronic cigarette, such that $28.9 \%$ of 
youth with a parent who owned an electronic cigarette reported lifetime use of an electronic cigarette. Given these findings, it is suggested that social contextual variables may play a role in adolescent electronic cigarette use.

Moreover, parental modeling of substance use, not having clear boundaries or rules regarding drug use, and/or communication barriers, particularly in regards to drug-specific communication, have been associated with adolescent use of tobacco (Pentz \& Riggs, 2013). Other studies (e.g., Mahabee-Gittens, Xiao, Gordon, \& Khoury, 2013) have shown that an increased risk of adolescent smoking is associated with adolescents being from single-parent homes, having parents of lower levels of education, and having parents with a prior smoking history. Given similar research findings, the 2015 Report of the Surgeon General also includes a Call for Action with a section partially devoted to improving parent knowledge and involvement in prevention of youth electronic cigarette use (CDC, 2015). The report recommends specific strategies for parents, such as improving support, encouragement, and open communication with youth about the harms of nicotine and tobacco use; patronizing the use of electronic cigarettes and other tobacco products; modeling appropriate avoidance of electronic cigarettes and other tobacco products (setting an example); and ensuring youth environments (including the home) are completely free of any tobacco products, including electronic cigarettes (CDC, 2015).

Parental information and behavior management strategies. Relevant to these CDC (2015) recommendations is parental approach to managing their adolescent's behavior and to establishing lines of communication. Though research examining the relation between electronic cigarette use and these particular parental factors is limited, a large basis of information is available in the tobacco literature. The specific parental strategies of focus include parental behavioral control, parental knowledge, and parental solicitation. Closeness and supportiveness 
(as opposed to conflict) in the relationship with caregivers also has been explored as a protective factor against adolescent smoking behaviors.

Parental behavioral control. Parental behavioral control refers generally to actions taken by a parent to manage youth behavior. This construct may take a variety of forms, such as practices that establish structure within a family (e.g., establishing a time when the family checks in via phone during outings) and enforce a set of rules with the goal of regulating and controlling youth behavior (e.g., grounding, other disciplinary practices). Other limit setting behaviors specific to the youth (e.g., setting a curfew) are included in this construct as well (Bean, Barber, \& Crane, 2006; Kerr \& Stattin, 2000; Kerr, Stattin, \& Burk, 2010; Kerr, Stattin, \& Özdemir, 2012). Finally, another dimension of parental control is the extent to which parents require the adolescent to reveal information about their whereabouts, activities, or peers. Though related to parental solicitation, or asking about this information, parental behavioral control is distinct in that its focus is on that of setting and verbalizing behavioral limits (Kerr \& Stattin, 2000; Fletcher, Steinberg \& Williams-Wheeler, 2004).

Research in the area of parental behavioral control has been mixed, as some studies have suggested behavioral control by parents to be a protective factor for adolescent problem behaviors (including use of tobacco, alcohol and other substances), in general, and others have not shared the same findings. For example, Mahabee-Gittens and colleagues (2013) suggested a negative association between punishment (behavioral control) behaviors and problematic adolescent behaviors, potentially indicating a protective nature of parental behavioral control. In contrast, other research has suggested that parental behavioral control methods could potentially backfire, providing correlations in the opposite direction. For instance, a few studies (e.g., Kerr, Stattin, \& Burk, 2010; Vieno, Nation, Pastore, \& Santinello, 2009) have suggested a relation 
between lessened adolescent disclosure behaviors with parents who have created and enforced rules requiring adolescent disclosure (i.e., increased parental control). It is important to note that though discussions of these topics in the literature often suggest directionality, studies often are rooted in correlational data, which does not permit inferring causality or directionality. As such, inconsistency in the literature may be due, in part, to the bidirectional relations between adolescent and parenting behaviors.

Parental knowledge and monitoring. There has been some recent evidence to suggest that parental knowledge and specific parental monitoring strategies can be significant protective factors against adolescents engaging in risk behaviors, including the use of tobacco. Whereas parental knowledge includes more global knowledge of adolescents' social companions, whereabouts, and activities, a related construct is parental monitoring, which refers generally to parental strategies and behaviors used to obtain this knowledge. These strategies may take a series of different forms, one of which could be having rules about spending time with friends and permissions needed prior to engaging in certain activities and reactions following disobedience to these rules (CDC, 2012a). This is also related to parental behavioral control, which would involve the behavioral means of enforcing these rules. Parental monitoring may also take the form of active surveillance or supervision of youth behaviors (e.g., checking on a teen's internet and cell-phone usage, calling the youth while they are out with their friends), as well as general expectations parents have for the behavior their teen should engage in (CDC, 2012a). Finally, monitoring may also take the form of parental efforts to get to know a teen's friends and the parents of their teen's friends (CDC, 2012a). The latter form is also related to parental solicitation, which is asking the teen (or the teen's friends) about activities they engage in. 
A few studies have shown parental monitoring and knowledge to be highly protective through the age of 16 years (Mahabee-Gittens, et al., 2013; Soenens, Vansteenkiste, Luyckx, \& Goossens, 2006). Additionally, though research is currently limited in regards to specific parent behaviors as protective factors against electronic cigarette use, a recent study has shown parental monitoring and parental support to be negatively correlated with adolescent use of electronic cigarettes (Wills et al., 2015). While this study involved a large sample size ( $\mathrm{n}=1941$ students) and has shown initial evidence that parental behaviors may serve a protective function for adolescent use of electronic cigarettes, a major limitation of this study is that it was conducted solely with adolescents in Hawaii. Moreover, additional research is needed to examine the generalizability of these findings to other adolescent populations.

Aside from the study conducted by Wills and his colleagues (2015), other research (e.g., Tilton-Weaver, 2014) has suggested a link between parental knowledge and youth disclosure, suggesting that parents are more informed about their child's whereabouts and activities when adolescents are more open to providing information to them. This not only makes intuitive sense, but also shows the beginning of an important exploration into the interactive connections between adolescent and parental behaviors and how parent and youth behaviors and communication influence one another bidirectionally (Keijsers, Branje, VanderValk \& Meeus, 2010, Tilton-Weaver, 2014). Similarly, in regards to electronic cigarette use, Wills and colleagues (2015) found that adolescents who used electronic cigarettes, in contrast to those who did not, reported lower perceived levels of parental monitoring, supporting the contention that parental knowledge is related to adolescent problem behaviors.

Parental solicitation. Solicitation, or the act of parents initiating conversation regarding adolescent behavior and activities, has been met with mixed results. While Keijsers, Frijns, 
Branje, and Meeus, (2009) found parental solicitation to be negatively correlated with baseline reports of adolescent problem behaviors, the same relation did not hold true for follow-up assessments. These findings suggest that levels of parental solicitation may not only change over the course of adolescent development, but its impact on adolescent behavior may change over time as well (e.g., Eaton, Krueger, Johnson, McGue, \& Iacono, 2009). Likewise, parental solicitation has been identified in some studies as a risk—rather than a protective - factor for adolescent problem behavior. By example, Metzger and colleagues (2013) observed a positive association between maternal solicitation and the likelihood of adolescents to increase their smoking behavior over a two-year trajectory. It is important to note that trend was not observed for paternal solicitation, as expected (Metzger, et al., 2013). Similar to this study, having parents who socialize more frequently with their children about smoking-related topics has been related to adolescent smoking (Harakeh, Scholte, de Vries, \& Engels, 2005). In other words, the more parents talk with their child about smoking, the more likely the child is to engage in smoking behaviors. As a result, this particular finding may be related to the parental behavior of asking for information from their children.

Given the inconsistencies across the literature, it is important for researchers to continue to explore and clarify the relation of parental solicitation to adolescent problem behaviors and the extent to which it may be a protective or risk factor for these behaviors. Similarly, parental solicitation should be included in developing and testing theoretical conceptualizations of adolescent problem behaviors, such as smoking traditional and electronic cigarettes, particularly in terms of the development and maintenance of these behaviors.

Adolescent information management strategies. Just as parental behaviors may factor into an adolescent's likelihood of engaging in smoking and other problem behaviors, certain 
characteristics of adolescents also may be associated with risk behaviors. One of these characteristics is use of information management strategies, particularly disclosure and secrecy. Youth disclosure, or an adolescent's willingness to divulge information to his or her parent or caregiver, and youth secrecy, an adolescent's unwillingness to divulge information, have proven to be interesting areas to explore given the mixed findings associated with them. Much of the information we currently have on these strategies began with the work of researchers Kerr and Stattin (2000) on adolescent disclosure. Since this time, others have broadened their definition to account for and parse out individuals who disclose part - but not all—of the information their parents request from them (referred to as partial disclosure) or omit major details; also included are those who withhold all information completely (secrecy), and those who attempt to mislead caregivers through lying (e.g., Metzger et al., 2013). Similarly, while disclosure and secrecy were originally understood as a single construct viewed on a spectrum; recent and compelling findings have provided support for viewing the two as separate, distinct variables (e.g., Keijsers et al., 2010; Tilton-Weaver, 2014).

Additional research has focused on why adolescents disclose or keep secrets from their parents. Recent studies have suggested that adolescents withhold important details or maintain secrecy due to engagement in problem behaviors, such as smoking (e.g., Keijsers et al., 2010; Kerr \& Stattin, 2000). Contrary to this evidence, other research has suggested that secrecy is far more complex and may also be the result of perceived parental invasion of privacy (Hawk, Jansen, \& Jellesma, 2012) or a lack of perceived parental support or trust (Keijsers et al., 2010). Adolescent disclosure and secrecy. There are a number of factors that can influence an adolescent's engagement in information management strategies, such as disclosure and secrecy. In particular, perceptions of parental disapproval, perceptions regarding the extent of the problem 
behavior (e.g., not viewing the behavior as a problem), the type of behavior involved in (e.g., multifaceted and prudential), the age of the adolescent (e.g., early versus middle adolescence), and the personal goals of greater independence from parents and caregivers all are contributing factors (Smetana, Villalobos, Tasopoulos-Chan, Gettman, \& Campione-Barr, 2009). These are important considerations in understanding and conceptualizing adolescent problem behaviors in relation to caregivers, as research has suggested that these adolescent-initiated behaviors are often predictors of parental knowledge of those problem behaviors (Kerr, Stattin, \& Burk, 2010). Indeed, adolescents disclose to their caregivers when their caregivers monitor their behaviors (especially if they have a tendency to accept parental authority), when the adolescent is not currently involved in problem behaviors, and when adolescents perceive high levels of support from their caregivers (Tilton-Weaver, 2014). Tilton-Weaver (2014) found support for many of these claims, reporting that delinquency is reciprocally related to secrecy in adolescence. In other words, having current involvement in delinquent behaviors was associated with increased levels of secrecy, while maintaining a higher number of secrets also is related to higher levels of delinquent behaviors.

Bidirectional relations between parent and youth strategies. Researchers also have explored the bidirectional, longitudinal association between adolescent information management strategies, parental behaviors, and adolescent problem behaviors (Metzger et al., 2013). Results have indicated that above other related variables (e.g., demographic characteristics, initial smoking patterns, other parenting characteristics), maternal solicitation and youth secrecy were significantly related to the smoking trajectories of youth (Metzger et al., 2013). In particular, adolescents were more likely to have escalated smoking behaviors two years later if they engaged in more active secrecy and had mothers who often engaged in conversations about 
smoking behaviors with them (Metzger et al., 2013). Metzger and colleagues (2013) also found that parental knowledge was significantly associated with initiation of conversations between parents and youth about smoking and that adolescents were more likely to engage in disclosure during these conversations if their parents had previous knowledge of their behaviors. Further, a positive association was found between adolescent secrecy and high levels of behavioral control (e.g., many rules about substance use), such that teens were more likely to engage in active secrecy with their mothers when the family appeared to had high levels of behavioral control.

\section{Summary and Rationale for Current Study}

Because certain parental factors and adolescent management strategies have led to somewhat inconsistent results when examining their relation to adolescent problem behaviors, such as tobacco use, there are important limitations of this research that deserve consideration. Firstly, the majority of the above-mentioned studies are not longitudinal in nature and are of varying sample sizes, potentially impacting the conclusions that can be made. Secondly, much of the research regarding these variables is based on international data, which may or may not be generalizable to the U.S. population. Though some studies (e.g., Metzger et al., 2013) have begun examining adolescent information management strategies and parental factors in samples of U.S. adolescents, research in the area is relatively lacking, particularly in relation to adolescent use of electronic cigarettes. Thirdly, although the general tobacco literature for adolescents is useful to consider, there can be unique factors tied to electronic cigarette use that make this particular health-risk behavior distinctive. Some factors unique to electronic cigarettes can be: (a) perceived health benefits relative to traditional cigarettes (e.g., due to advertising, peer rumors); (b) relative ease in cloaking use from others (e.g., odor in clothes is much less than 
traditional cigarettes), like parents; and (c) enhanced appeal (e.g., wide range of possible flavors, many of which are sweet or interesting to youth; social benefits).

Given that adolescent use of electronic cigarettes has been far less researched than other adolescent problem behaviors (e.g., cigarette smoking), it is possible that findings with this newer adolescent health behavior may vary from extant results. Indeed, as indicated in the review of the literature, recent studies suggest the potential for discovering interesting and important associations among adolescent information management and parental variables in relation to electronic cigarette use (e.g., Wills et al., 2015). In all, it is apparent that while parents and caregivers have a significant impact on their adolescent's behavior, adolescents simultaneously influence their parents' behavior as well. As such, a bidirectional relationship exists. Moreover, research efforts should move toward a focus on acknowledging this interplay to develop a clearer conceptualization of how it relates to adolescent problem behaviors, such as adolescent use of electronic cigarettes.

The current study addresses this goal by examining the dynamic interplay of parent and adolescent behaviors and information management strategies via the use of a person-oriented methodology. The goal of this person-centered approach is to explore these complex interactions while also accounting for individual differences. A cluster analysis accomplishes this goal by grouping cases based on shared characteristics across the set of variables included in analysis (Bergman , Magnusson, \& El-Khouri, 2003; Hair et al., 2006). With the current study in mind, cluster analysis allows for the examination of patterns of adolescent information management and parental information and behavior management strategies. After these patterns are identified, the second portion of analysis focuses on grouping respondents into "clusters" on the basis of these shared patterns (Hair et al., 2006). Consequently, the main objective of the current study 
was to explore electronic cigarette use among adolescents and create a profile of use based on parent behavior and information management strategies and youth information management strategies. As such, this study had 3 primary aims:

Aim 1. The first aim involved investigating group differences and identifying potential covariates between 3 types of electronic cigarette users: (1) never users, as defined by no lifetime use of an electronic cigarette or conventional cigarette; (2) electronic cigarette only users, as defined by any lifetime use of electronic cigarettes and no history of conventional cigarette use; and (3) dual cigarette users, as defined by any lifetime use of both electronic and conventional cigarettes.

Hypothesis: Based on inconsistency in the electronic cigarette literature, no specific $a$ priori hypotheses regarding demographic covariates were made. However, prior research indicated that gender, age, and family status (intact, blended, or single-parent families) may play a role in differences across groups. While it would have been reasonable based on more consistency in the literature to expect racial/ethnic differences to emerge, it was anticipated the locations of recruitment for this study would yield a primarily Caucasian sample across all groups. As such, it was determined that racial differences would not be able to be fully assessed in the current study.

Aim 2. The second aim consisted of identifying clusters of adolescent information management strategies and parental information and behavior management strategies reported by high school students.

Hypothesis: Given that Aim 2 is exploratory in nature and research in this area is limited, a specific a priori hypothesis regarding the number of clusters was not identified. 
Aim 3. The third aim involved using the clusters identified in Aim 2 to describe differences among the 3 types of electronic cigarette users: (1) never users, (2) electronic cigarette only users, and (3) dual cigarette users.

Hypothesis: Although Aim 3 is exploratory in nature, it was expected that clusters of adolescent electronic cigarette use will vary based on adolescent information management strategies and parental factors. For example, higher secrecy and lower disclosure by adolescents as well as lower parental knowledge may be associated with adolescent electronic cigarette only users and/or dual cigarette users as compared to never users.

\section{Method}

\section{Participants}

A total of 566 adolescents participated in the current study. These students were recruited from high schools in Ohio, West Virginia, and Pennsylvania, as well as through the Adolescent Medicine clinic of West Virginia University Health Sciences Center. Inclusion criteria for youth were as follows: (1) currently enrolled in high school; (2) aged 13-18 years; and (3) fluent in the English language, as study questionnaires were only administered in English. Students who met these criteria were excluded from the current study if they were identified by teaching or medical staff as having significant cognitive impairments impeding their ability to complete the questionnaires without substantial assistance.

\section{Procedure}

The current study was an expansion of a dissertation project that examined a large range of risk factors for adolescent electronic cigarette use. As such, approval from the Institutional Review Board at West Virginia University was obtained and permission granted from the participating high schools' administrations prior to data collection. Medical staff members for 
the Adolescent Medicine Clinic also granted permission for our research team to recruit participants from their clinics.

School settings. Recruitment and data collection occurred during typical class meetings. Research staff provided students with a brief description of the study, including its purpose, inclusion criteria, participation requirements, confidentiality, and the potential risks and benefits of participation. Simultaneously, informed consent forms and recruitment letters describing the project were distributed to the youth. After this discussion, students were offered a chance to have their immediate questions answered. Afterward, a brief description of the consent process occurred. Written consent was required of all parents of youth under the age of 18, while written consent (age 18) and assent (age younger than 18) were required of all youth. Youth were informed that if they returned their consent and assent forms fully completed (including all required signatures), regardless of whether they would participate in the study, they would be entered into a lottery for the chance to win one of ten $\$ 20$ gift cards. Youth were also informed that the drawing would occur after all data collection was complete to ensure equal chances of winning among the various recruitment locations. Additionally, a check-box was included on the consent form above the signature lines to indicate their desire or refusal to participate in the study. Combined, these procedures facilitated the process of tracking recruitment in terms of participation and refusal rates.

Approximately 2-7 days after distributing consent/assent forms, the research staff returned for a second visit to the classroom (also during routinely scheduled class periods) to collect the signed consent and assent forms. The participants then completed the packet of questionnaires comprised of the following measures: (1) Student Information Form; (2) Youth Risk Behavior Survey; (3) Parental Behavioral Control Scale (4) Parental Knowledge Measure; 
(4) Parental Solicitation Measure; and (6) Youth Disclosure Scale. Additional questionnaires

were included in the packet for the overarching dissertation project, though these measures were not used or analyzed for the current study.

After completion of this packet, the students then received an additional lottery ticket for a chance to win one of fifty $\$ 20$ gift cards. This lottery was separate from the consent form lottery, as the second drawing only included participating students. Like the consent form drawing, names for the participation lottery were drawn at the completion of all data collection to ensure equal chances of winning.

Clinic setting. Recruitment and data collection in the clinic occurred during routinely scheduled appointments. Per IRB approval, medical staff team members (e.g., physician, nurse) first approached the patients and asked if they were interested in speaking with the researcher about the study. Consistent with procedures in the school setting, for those families interested in taking part in the study, research personnel obtained consent from caregivers and consent or assent from patients. Given that in many instances, adolescents attend clinic with their caregiver or legal guardian, adolescents were not required to take forms home and return them at a later point in time. As such, these participants were not entered into the first lottery. However, youth recruited from the clinic setting were entered into the second lottery drawing if the youth completed the questionnaire packet. This drawing also occurred upon completion of the study.

\section{Measures}

The current study utilized a series of self-report measures to provide descriptive information for the sample as well as to assess for use of electronic cigarettes and the following constructs of interest: (1) parental behavioral control, (2) parental knowledge regarding 
adolescent problem behaviors, (3) parental solicitation, (4) youth disclosure, and (5) youth secrecy.

Student Information Form (SIF). The SIF was created for the overarching dissertation study, with the purpose of gathering demographic information from participants. In particular, the following variables were collected and analyzed in the current study: age; grade/year in school; gender; race and ethnicity, including Caucasian, African-American, Asian-American, Hispanic-American, Bi-Racial/Mixed Race, and Other; parental marital status, including never been married/single, separated, divorced/single, married to other biological parent, remarried to step-parent, living with boyfriend/girlfriend, and widowed; and maternal and paternal education level, ranging from $6^{\text {th }}$ grade or less to Master's degree or doctoral degree. Race, parental marital status, and parental education level were recoded to combine categories, given the relatively small cell sizes. An overview of the coding of demographic variables can be found in Table 1.

\section{Youth Risk Behavior Survey (YRBS) (Centers for Disease Control and Prevention,}

2015). The YRBS is an 89-item self-report questionnaire designed to assess a series of healthrisk behaviors, including the following: (1) behaviors contributing to unintentional injuries and violence; (2) sexual risk-taking behaviors; (3) alcohol and other illicit drug use; (4) use of tobacco products; (5) unhealthy eating and diet habits; and (6) inadequate amounts of physical activity. Each item of the YRBS is treated as a separate score and there are no subscales, though similar items (e.g., tobacco use) are grouped together. Responses to the items are recorded in a multiple-choice format.

For the purposes of the current study - that is, to identify adolescent use of electronic cigarettes - adolescents were grouped into categories of responses based on several items from the YRBS, as described in Table 1. The first YRBS item (YRBS 1) asks participants to indicate 
if they have ever tried cigarette smoking in their lifetime, including one or two puffs (yes/no response option). The third YRBS item (YRBS 3) asks participants to indicate the frequency of their use of cigarettes during the past 30 days on a 7-point scale from "0 days" to "All 30 days." YRBS 14 and YRBS 15 follow the same pattern. YRBS 14 asks participants to indicate if they have ever used an electronic vapor product with a yes/no response option. YRBS 15 asks participants to indicate the frequency of their use of electronic vapor products in the past 30 days on a 7-point scale ranging from " 0 days" to "All 30 days." A coding algorithm was created for the current study to group participants into one of three categories: (a) never used an electronic cigarette ("never users"), (b) have tried or experimented with electronic cigarettes at least once in their lifetime ("ever/lifetime users"), and (c) have ever tried or experimented with both electronic cigarettes and conventional cigarettes at least once in their lifetime ("dual users"). Never users included participants who responded "no" to YRBS 1 and YRBS 14. Electronic cigarette only users included participants who indicated "yes" on YRBS 14 or a frequency greater than zero on YRBS 15. These participants also indicated "no" on YRBS 1. Dual users included youth who indicated "yes" to both YRBS 1 and YRBS 14 or a frequency greater than zero on both YRBS 3 and 15. Conventional cigarette only users ("yes" to YRBS 1 and "no" to YRBS 14) were not included in analyses $(n=24)$.

Psychometric data for the 2015 version of the YRBS are currently unavailable because the YRBS is revised every two years by the Centers for Disease Control and Prevention (CDC). Despite this, prior psychometric examinations suggest that the YRBS has adequate evidence of reliability (consistency over time), particularly in terms of identifying lifetime cigarette use when administered to students in the eighth grade or above (Brener, Collins, Kann, Warren, \& Williams, 1995; Brener et al., 2002). Further, other studies, such as a review conducted by 
Brener, Billy, and Grady (2003), has suggested evidence of validity among adolescent selfreports of substance use. While cognitive and situational factors can affect many health-risk behaviors, such as substance use, findings also emphasize the importance of utilizing self-report, as they are often comparable to biochemical measures, such as the level of carbon monoxide (CO) in exhaled air; cotinine in plasma, saliva, or urine; and thiocyanate in plasma or saliva (Brener, Billy, \& Grady, 2003). Though these biomarker measures have their own limitations, they are often considered the gold standard for objective measurement of adolescent substance use. As such, having comparable findings between these biomarkers and self-report instruments, such as the YRBS, provides evidence supporting the validity of adolescent responses.

\section{Parental Behavioral Control (PBC) (Kerr \& Stattin, 2000; Kerr, Stattin, \& Burk,} 2010; Kerr, Stattin, \& Özdemir, 2012). Parental Behavioral Control (PBC) is a 5-item selfreport questionnaire assessing youth perception of parental efforts to control their behavior outside of the home (e.g., "Do you need to have your parents' permission to stay out late on a weekday evening?"). Response options are given on a 5-point Likert-type scale, ranging from "yes, always" (1) to "no, never" (5). Psychometric information for this measure is limited; however, reported Cronbach's alpha reliabilities range from .78 to .85 and similar evidence was found for 2-month test-retest reliability, $r=.82$ (Kerr \& Stattin, 2000). In 2010, Kerr, Stattin, and Burk (2010) conducted an additional longitudinal study with a sample of 938 adolescents in which data were compared across two time points, collected 2 years apart. During this study, evidence of internal consistency was found to be sufficient, with Cronbach's alpha reliabilities of .79 and .84 , respectively. After reverse scoring the measure, higher scores indicate higher parental behavioral control. Cronbach's alpha reliability in the current sample was .87 . 


\section{Parental Knowledge Measure (PKM) (Kerr \& Stattin, 2000; Stattin \& Kerr, 2000).}

The PKM is a four-item assessment of youth perception of parent insight into their activities and behaviors (e.g., "Do your parents usually know what you do after school?"). For the purposes of the current study, two additional items were added to this measure relating specifically to electronic cigarettes ("Do your parents know when you use e-cigarettes?" and "Do your parents know who you use e-cigarettes with [e.g., which friends]?”). This measure uses a 5-point Likerttype scaling method, with varying response options ranging from 1 to 5 (e.g., "almost always" to "never," "has not happened" to "most of the time"). Psychometric information for this measure is limited in that this measure has gone through revision over time. By example, past versions of this measure included 9 items, with Cronbach's alpha reliability ranging from $.85-.87$ and 2month test-retest reliability of .83 (Kerr, Stattin, \& Burk, 2010; Stattin \& Kerr, 2000). In a later study conducted by Kerr, Stattin, and Özdemir (2012), this measure was modified to four items to improve consistency with current conceptualizations of parental supervision (e.g., Lamborn et al, 1991) and to decrease overlap with the measure of parental behavioral control. After revisions, Cronbach's alpha reliability ranged from .76 to .78, consistent with Lamborn and colleagues (1991). After reverse scoring the measure, higher scores indicate higher levels of parental knowledge. Unfortunately, Cronbach's alpha reliability in the current sample was significantly less than acceptable, with a value of .44 . This may be the result of not enough youth in the sample using electronic cigarettes. Moreover, when the reliability analysis was conducted only with the original four items (no electronic cigarette items), Cronbach's alpha reliability was .73. However, it is important to note that when reliability was conducted on the two electronic cigarette items for the specific sub-sample of lifetime e-cigarette and dual users, Cronbach's alpha reliability was .87 . These two items also were found to be adequately correlated with one 
another $(r=.77)$ for the total sample. Additionally, when examining the correlation between summary scores for the original 4-item scale and the two combined electronic cigarette items, the two were negatively correlated with a Pearson's correlation coefficient of -.235. As such, it is likely that the two electronic cigarette items significantly contributed to the low reliability found in the combined 7-item scale.

\section{Parental Solicitation Measure (PSM) (Kerr \& Stattin, 2000; Kerr, Stattin, \& Burk,}

2010). The PSM is a 5-item self-report measure completed by youth. The purpose of the measure is to assess the extent to which a child perceives his or her parents as seeking out or asking for information from them, particularly in regards to activities outside of the home. Similar to the measure of parental knowledge, two items were added to this measure to address the goals of the current project. These items are specific to electronic cigarette use ("How often do your parents try to talk to you about e-cigarettes [e.g., ask you if you know what they are]?"and "How often do your parents try to talk to you about your use of e-cigarettes [how often you use them, with whom, etc.]?"). These items comprise a 5-point Likert-type response format, ranging from 1 to 5 with varying corresponding response options (i.e., $1=$ very often to $5=$ almost never; $1=$ several times a week to 5=no). Though, the full psychometric information for the PSM was currently unavailable, a Cronbach's alpha reliability of .70 was reported, with a 2-month test-retest correlation of .84, based on sample of 1,186 adolescents in Sweden (Kerr \& Stattin, 2000). A later longitudinal study conducted in 2010 with 938 Swedish adolescents found similar Cronbach's alpha reliabilities of .70 and .72 across a two-year time period (Kerr, Stattin, \& Burk, 2010). After reverse scoring the measure, higher scores indicate higher parental solicitation.

Cronbach's alpha reliability in the current sample was .74. When the reliability analysis was conducted solely on the original five items (no electronic cigarette items), Cronbach's alpha 
reliability was .81 . Additionally, when reliability was conducted on the two electronic cigarette items for the specific sub-sample of lifetime e-cigarette and dual users, Cronbach's alpha reliability was .73 . These two items also were found to be moderately correlated for the total sample $(r=.57)$. Finally, the Pearson's correlation coefficient between summary scores for the original 5-item scale and the two electronic cigarette items, respectively, was low $(r=.12)$, which potentially contributed to the lower reliability found in the current study as compared to those utilizing the original measure.

\section{Youth Disclosure Scale (YDS) (Kerr \& Stattin, 2010; Kerr, Stattin, \& Özdemir,} 2012). The 2012 revised version of the YDS was used as a measure of adolescent information management strategies. The 5-item measure is separated into two distinct scales, one measuring adolescent disclosure (YDS-D, 2 items) and another measuring adolescent secrecy (YDS-S, 3 items). Moderate Cronbach's alpha reliabilities were reported for the subscales, with values ranging from .67-.72 for disclosure items and .77-.79 for secrecy items (Kerr \& Stattin, 2010). Combined, a Cronbach's alpha reliability of .78 has been noted for the 5-item scale, with a 2month test-retest reliability of .70 (Kerr \& Stattin, 2010).

Given our primary aims to identify and describe adolescent information management strategies as they relate to electronic cigarette use, three additional items were crafted and included in the YDS. Specifically, two items were added to the disclosure subscale ("Do you tell your parents about your use of e-cigarettes?" and "Do you talk with your parents about your friends' use of e-cigarettes?") and one item added to the secrecy subscale ("How often do you try and keep your use of e-cigarettes a secret from your parents?"). After reverse scoring each measure, higher scores indicate higher levels of youth disclosure and youth secrecy, respectively. For the disclosure subscale, Cronbach's alpha reliability in the current sample was lower than 
acceptable, with a value of .53. Again, this likely is the result of not enough youth in the sample using electronic cigarettes and youth not sure how to respond to the item if they do not use them. Again, when removing each item relevant to e-cigarette use, one at a time, the Cronbach's alpha did not increase to an acceptable level (i.e., $\alpha=.58$ and $\alpha=.52$, respectively). However, when reliability analysis was conducted again on the original three items (no electronic cigarette items included in analysis), Cronbach's alpha reliability was .80. It is also important to note that when reliability was conducted on the two disclosure-based electronic cigarette items for the specific sub-sample of lifetime e-cigarette and dual users, Cronbach's alpha reliability was .84. These two items also were found to be positively correlated with an inter-item correlation coefficient of .72. Finally, the correlation between summary scores for the original 3 -item scale and the two combined electronic cigarette items was negative and low $(r=-.12)$, which potentially contributed to the lower reliability found in the current study as compared to those utilizing the original measure.

For the secrecy subscale, Cronbach's alpha reliability was .72 with the electronic cigarette item included. However, reliability analysis indicated that Cronbach's alpha reliability increased to .85 with the electronic cigarette item removed. Interestingly, when reliability analysis was conducted again for the sub-sample of e-cigarette and dual users, Cronbach's alpha reliability was .64. As such Cronbach's alpha reliability increased to .83 if the electronic cigarette item was deleted. 


\section{Results}

\section{Preliminary Analyses}

Recruitment rates. A total of 1,131 adolescents were asked to participate in this study, with 565 of them participating, resulting in an average recruitment rate of $49.96 \%$. Recruitment percentages ranged across sites, most dramatically in the school settings. Recruitment rates ranged from $29.03 \%$ to $77.0 \%$, with the highest recruitment percentage in the adolescent medicine clinic. It is likely that the lower rates of recruitment in the school setting may be due to the gap in time between providing consent forms and participation (2-7 days later), particularly given that many students indicated that they had forgotten to have their parent sign their consent form or they had left it at home. Additionally, ten students were absent on the date of data collection and only nine students returned their consent forms indicating that they (or their parents) did not consent to participation. In all, $90.3 \%$ of adolescents in the study were recruited from high school settings.

Data screening. As a preliminary step to data analysis, data were reviewed for missing values. Missing values analysis was also conducted to determine if data were missing at random. Rates of missing data for individual variables ranged from $0 \%$ to $6.9 \%$, with a total of $9.89 \%$ of participants missing data on at least one of the variables utilized in the primary analyses. Little's MCAR test indicated that data were missing at random $\left(X^{2}(172, \mathrm{n}=565)=91.378 p=1.00\right.$. Imputation using the Expectation-Maximization algorithm was used for all participants, as no participants were missing more than $20 \%$ of items on any given questionnaire.

Following missing value analysis and imputation, bivariate scatterplots were scanned, resulting in no problems of heteroscedasticity or linear associations. Additionally, a multiple linear regression was utilized to screen data for multicollinearity and multivariate outliers. 
Tolerance $\geq .40$ and VIF $\leq 4.0$ were utilized as cut-off values for identifying problems with multicollinearity. Collinearity statistics revealed no potential issues with any of the information management strategy variables, including Parental Behavioral Control $(\mathrm{PBC}$; Tolerance $=.82$; VIF = 1.2), Parental Knowledge $(\mathrm{PKM} ;$ Tolerance $=.67 ; \mathrm{VIF}=1.48)$, Parental Solicitation $(\mathrm{PSM} ;$ Tolerance $=.60 ; \mathrm{VIF}=1.67)$, Youth Disclosure $($ YDS-D; Tolerance $=.52 ; \mathrm{VIF}=1.93)$ or Youth Secrecy (YDS-S; Tolerance $=.95 ;$ VIF = 1.06). To identify multivariate outliers, Mahalanobis distance tests with a critical value of 15.09 was used. Three cases exceeded this critical value, leading to their removal prior to subsequent analyses. This resulted in a new sample size of 562 participants.

Descriptive statistics. Descriptives were computed to analyze demographic characteristics (Table 2), frequency of electronic cigarette use (Table 2), and outcome variables (Table 3) for the current sample. Participants were primarily female and Caucasian. The largest percentage of participants were in their sophomore (second) year of high school, resulting in an average age of 15 years. Most adolescents reported being from an intact (two-parent) household, with well-educated parents (bachelor's degree). Outcome variables were tested for skewness and kurtosis, resulting in a number of concerns (Table 4). Appropriate transformations were attempted for values of 2 or more, often resulting in worsened skew or kurtosis for multiple variables. As such, it was determined that the original data should be utilized for analyses, though interpreted with caution. Violations of normality also make conceptual sense in this sample as the majority of participants were not electronic cigarette users, yet many of the primary outcome variables included questions on electronic cigarette usage.

Following exploration of demographic and primary outcome variables, descriptive and frequency data were analyzed for variables related to electronic cigarette use. It should be noted 
that 24 youth (4.2\% of the sample) were not included due to coding of the user group variable because their responses classified them as having used conventional cigarettes only, and this group was not a focus of the current study. As such, these participants were excluded from all analyses addressing the aims of this study; however, they were included in the results below.

Based on the results from the descriptive and frequency statistics, a total of $39.0 \%$ $(n=219)$ adolescents reported ever use (at least one puff once in their lifetime) of electronic cigarettes. Of this percentage, $57.1 \%$ of youth $(n=125)$ indicated dual use of electronic cigarettes and conventional cigarettes at least once in their lifetime. Consequently, the frequency of participants in each user group were as follows: $56.8 \%$ never user, $16.7 \%$ electronic cigarette only user, and $22.2 \%$ dual user (electronic and conventional cigarette user). In reviewing current use (at least 1 electronic cigarette in the past 30 days) among our sample's electronic cigarette only users and dual users (defined as having had any lifetime use), the majority of youth indicated that they were not currently using an electronic cigarette $(n=119,53.6 \%)$. Table 5 provides a more detailed description of the frequency of current use among this sub-sample.

Aim 1. The first aim of the study was to explore group differences between the three groups of electronic cigarette users. Differences based on gender, year in school, family status, parental education, and all parent and youth behavior and information management strategies were examined. To identify potential group differences or covariates, a series of chi-square and one-way ANOVA analyses were conducted.

First, to address potential differences between gender and user group, a chi square analysis was conducted, resulting in no significant differences in gender across user types $(\mathrm{n}=$ $541), X^{2}(2)=5.78 p=.055$. Second, year in school, ranging from freshman (grade 9) to senior (grade 12), was significantly different by user group $(\mathrm{n}=541), X^{2}(6)=45.04 p<.001, p h i=.29$. 
To break down this significant finding and determine which groups significantly differed, posthoc cell-by-cell comparisons were conducted utilizing a Bonferroni correction. Results indicated that seniors were more likely to be dual users (42.3\%) compared to freshman (11.8\%), sophomores (15.3\%), and juniors (24.7\%). Similarly seniors were least likely to be never users (36.9\%) as compared to freshman (75\%), sophomores $(63.3 \%)$, and juniors $(62.7 \%)$. No significant differences emerged across grade classification for the electronic cigarette only group $(\mathrm{p}>$.05). Third, family status (intact, single parent, blended/other) significantly varied by user group $(\mathrm{n}=542), X^{2}(4)=31.68, p<.001, p h i=.24$. Similar to grade classification, in conducting post-hoc cell-by-cell comparisons, statistically significant differences between particular groups emerged. For example, youth from intact families were significantly more likely to be in the never-user group (68.7\%) as compared to youth from single parent families $(44.8 \%)$ or blended/other family types (44.1\%). Inversely, youth from intact families were significantly less likely to be in the electronic cigarette only group (13.2\%)) or dual user group (18.1\%) as compared to youth from single-parent families (23.8\% and $31.4 \%$, respectively) and blended/other family types ( $24.3 \%$ and $31.5 \%$, respectively). Fourth, in assessing parental education, significant differences were found between levels of maternal education and user group $(\mathrm{n}=531), X^{2}(8)=41.19, p<.001, p h i=.28$. When examining post-hoc cell-by-cell comparisons, multiple significant differences emerged. Youth who reported having a mother with a Master's degree or above were more likely to be never users (70.2\%) as compared to youth whose mothers had some college or specialized/vocational training (50.4\%) or were a graduate of high school only (43.2\%). Youth who indicated their mother had a Bachelor's degree were also more likely to be in the never user group (66.0\%) as compared to those whose mother is only a high school graduate (43.2\%). No significant differences emerged between youth who 
indicated their mother had a Master's degree or above ( $70.2 \%$ of never users), a Bachelor's degree ( $66.0 \%$ of never users), or a mother that was not a high school graduate $(36.8 \%$ of never users). Inversely, youth who indicated having a mother that was a high school graduate only were significantly more likely to be dual users (47.4\%) as compared to youth with mothers who had a Bachelor's degree (18.9\%) or a Master's degree or above (9.6\%). In regards to dual use, youth with lower levels of maternal education (some college or specialized training and below) did not significantly differ from one another nor did youth with higher levels of maternal education (Bachelor's degree and above). Additionally, youth who reported their mother had a Bachelor's degree also did not significantly differ in likelihood of dual use when compared to youth who reported their mother had some college or specialized training. No significant differences emerged between levels of maternal education and youth who were electronic cigarette only users as well. Next, in assessing paternal education, significant differences were found across groups $(\mathrm{n}=514), X^{2}(8)=74.18, p<.001, p h i=.38$. In examining cell-by-cell comparisons, it was determined that youth with fathers who had a Bachelor's degree were significantly more likely to be never users $(75.3 \%)$ than youth whose fathers had lower levels of education, including some college or specialized training (46.8\%), only a high school graduate (39.3\%), or not a high school graduate $(34.8 \%)$. No significant differences emerged between youth with fathers who had a Bachelor's degree and those with fathers who had a Master's degree or above in regards to never use. No significant differences were also found among never users whose fathers had some college or specialized training and those who had fathers with lower levels of education (high school graduate or below). Among dual users, fathers were most likely to be a high school graduate only $(43.6 \%)$ or less than a high school graduate $(43.5 \%)$ as compared to youth with fathers who had a Bachelor's degree $(11.2 \%)$ or a Master's degree or 
above (14.7\%). For dual use, no significant differences were also found between youth whose fathers were high school graduates and those of lower levels of paternal education or youth whose fathers had specialized training/some college (21.6\%). For electronic cigarette only users, no significant differences were also found among the varying levels of paternal education.

To assess group differences on the key study variables (information management strategies), a one-way ANOVA was utilized. Though it should be noted that violations of normality exist in the current data, a one-way ANOVA has been determined to be particularly robust to this violation in large sample sizes. As such, the technique was determined appropriate. Additionally, given that the Levene's test was found to be significant across all information management variables (suggesting concerns with homogeneity of variance), Welch's $F$ test was used as a more robust test in the presence of this violation. Results indicated statistically significant differences in youth reports of parental behavioral control, Welch's $F(2$, 205.38)=6.96, $\mathrm{p}=.001$; parental knowledge, Welch's $F(2,172.31)=12.12, \mathrm{p}<.001 ;$ youth disclosure, Welch's $F(2,182.48)=6.27, \mathrm{p}<.001$; and youth secrecy, Welch's $F(2$, 171.28)=199.71, $\mathrm{p}<.001$. Results also indicated no statistically significant differences on parental solicitation between user groups. Games-Howell post-hoc analyses were conducted to determine the location of significant differences between groups. Results are displayed in Table 6.

Aim 2. To address this study's second aim, two cluster analyses (also known as Q analysis, classification analysis, typology, or numerical taxonomy) were conducted to identify clusters of adolescent information management strategies and parental behavioral and information management strategies as reported by high school students. First, an agglomerative, or hierarchical approach was taken, as this approach does not assume a pre-set number of 
clusters prior to grouping cases. Rather, this approach involves a series of steps in which it moves from every case being identified as in its own cluster to eventually combining all cases into a single cluster. During these "steps," an agglomeration schedule is created and yields associated coefficients for each stage. The researcher then looks for the largest "jump" in the values of the resulting coefficients. This "jump" is generally associated with an accurate estimation of the number of clusters that exist among the data. The agglomeration schedule for the current data can be found in Figure 1.

During visual inspection of the agglomeration schedule, three potential solutions were generated including a two-cluster-, three-cluster, and four-cluster solution. The agglomeration schedule also indicated the largest "jumps" occurred between steps 562 and 563 (three-cluster solution) and steps 563 and 564 (two-cluster solution). Next, the dendrogram (Figure 2), a graphical representation of number of clusters, was scanned to assist in determining the number of clusters for the data. The location where the parallel lines extend for a significant distance prior to re-combining help to determine the solution. The dendrogram also provided evidence for these solutions, particularly a two- or four-cluster solution. Examining these two methods (agglomeration schedule and the dendrogram) is important to ensure consistency in the findings.

After this agglomerative, or hierarchical approach, was completed, an iterative, or kmeans, approach was utilized in which the researcher had an a priori hypothesis regarding the number of clusters. This hypothesis was based on results from the hierarchical approach previously described (two-cluster, three-cluster, and four-cluster solutions). During this process, cases were assigned to a group based on the distance between their scores for the quantitative variables (e.g., youth disclosure, youth secrecy, parental knowledge, parental behavioral control, parental solicitation) and the centroid of the cluster. Then, multiple iterations were conducted to 
re-examine and re-evaluate these distances and divide cases into clusters. An iteration history was created, showing these iterations along with the amount of coordinate change of each cluster center, with the goal of achieving convergence. A chi-square analysis was conducted to check the amount of agreement between the k-means and hierarchical approaches for the two-, threeand four-cluster solutions to assist with determining which cluster solution was most appropriate. However, it was determined that the three- and four-cluster solution should not be chosen due to iterations failing to converge within 10 iterations. As such, the three- and four-cluster solutions were determined to have a poorer fit with the current data and the 2-cluster solution was used instead. Though not at $100 \%$ agreement, the two-cluster solution also yielded the highest percentage agreement as compared to the three- and four-cluster solutions, which agreed less than $50 \%$ in the determination of clusters by case.

Following the decision to use a two-cluster solution, a MANOVA was conducted to examine how the information management profiles differed on each of the parent and youth scales. The two profiles significantly differed in regards to youth secrecy, such that youth secrecy was greater for cluster $1(M=2.99, S D=1.00)$ than cluster $2(M=1.31, S D=.56)$. Similarly, youth disclosure $(\mathrm{M}=2.26, \mathrm{SD}=.69)$ was lower for cluster 1 as compared to cluster 2 $(\mathrm{M}=2.76, \mathrm{SD}=.61$. In regards to parenting strategies, parental behavioral control $(\mathrm{M}=3.58, \mathrm{SD}$ $=1.02)$, parental knowledge $(\mathrm{M}=2.83, \mathrm{SD}=.58)$, and parental solicitation $(\mathrm{M}=2.38, \mathrm{SD}=.71)$ were all lower in cluster 1 as compared to cluster 2.

The standardized mean frequencies of each type of information management profile are graphically displayed in Figure 3. The first cluster consists of individuals who are highly secretive and are more likely to have parents that are less likely to be behaviorally controlling, to solicit information from the adolescent regarding activities engaged in outside of the home, and 
less knowledgeable overall of the adolescent's activities outside of the home. The second cluster consists of less secretive youth who have parents who are more likely to engage in some behavioral control, solicitation of information, and have some knowledge regarding the adolescent's activities. These adolescents are also more likely to disclose information to their parents.

Aim 3. To describe differences in the 2-cluster solution based on user group, a chi-square analysis was applied. Results from this analysis indicated that user type was significantly related to cluster profile, $X^{2}(2, \mathrm{n}=542)=19.10, p<.001$, phi $=.477$. This result suggests that there is an association between user group and cluster profile with a medium to large effect size. In conducting post-hoc probabilities utilizing a Bonferroni correction, significant differences emerged between each of the user groups (never user, electronic cigarette only user, dual user) and the clusters $(\mathrm{p}<.008)$. Frequency statistics were also congruent with these findings, as it was determined that never users were more likely to be placed in the less secretive cluster $(78 \%$ of never users) as compared to electronic cigarette only users $(11.8 \%)$ and dual users $(10.2 \%)$.

A follow-up chi-square analysis indicated that gender was significantly related to cluster profile, $X^{2}(1, \mathrm{n}=565)=19.10, p<.001$. In conducting post-hoc probabilities with a Bonferroni correction, significant differences emerged between gender and the clusters $(\mathrm{p}<.013)$. Specifically, there were more females $(66.7 \%)$ in the less secretive profile as compared to males $(51.8 \%)$ in the secretive profile. A chi-square analysis of the differences between cluster and year in school (freshman, sophomore, junior, senior) was found to be non-significant, $X^{2}(3, \mathrm{n}=565)=$ $5.56 p=.135$. Conversely, a chi-square analysis of the differences between cluster and family status (intact, single, blended/other) was found to be significant with a small effect size, $X^{2}(2, \mathrm{n}$ $=565)=12.88, p<.01, p h i=.151$. In conducting post-hoc probabilities applying a Bonferroni 
correction, no significant differences emerged between family status groupings and the clusters $(\mathrm{p}<.008)$

\section{Discussion}

The current study had three exploratory aims: (1) to investigate group differences and identify potential covariates between three types of electronic cigarette users (never users, electronic cigarette only users, and dual users); (2) identify clusters of adolescent information management strategies and parental information and behavior management strategies; and (3) use the clusters identified in the second aim to describe differences among the three types of electronic cigarette users. Moreover, this study built on the existing electronic cigarette literature by gathering information about electronic cigarette use in high school students, as well as parent and youth behavioral and information management strategies using a profile-based approach.

\section{Electronic Cigarette Use Among Adolescents}

Prevalence rates of lifetime electronic cigarette use in the current study were comparable to other studies, suggesting that electronic cigarette use is relatively high among high school students (CDC, 2015; Kann et al., 2016; Wills et al., 2016). It is also important to note that dual use of electronic cigarettes and conventional cigarettes was slightly higher in the current sample than use of electronic cigarettes only (16.7\% and $22.2 \%$, respectively). These findings are consistent with recent research suggesting youth who experiment with electronic cigarettes are more likely than non-users to experiment with other tobacco products later, including smoking conventional cigarettes (CDC 2015; Wills et al., 2016). However, the cross-sectional, correlational nature of our data does not afford the opportunity to make this conclusion. Indeed, it could be youth who already smoke conventional cigarettes choose to use electronic cigarettes too (e.g., perhaps in places where smoking is prohibited, but vaping is not). 
In exploring differences across groups of electronic cigarette users (Aim 1), results indicated no significant gender differences across type of electronic cigarette user (never user, electronic cigarette only users, and dual users). While initial research on the interaction between electronic cigarettes and gender has been mixed, these results are consistent with the 2015 National Youth Tobacco Survey (NYTS), which noted no significant gender differences in lifetime use of electronic cigarettes among high school students (CDC, 2015). The 2015 NYTS also found no significant gender differences on susceptibility to using electronic cigarettes among non-users, potentially explaining why gender differences were not found in the current sample between non-users and electronic cigarette users (CDC, 2015).

Further, the current study revealed significant post-hoc differences between grade classification (year in school) and electronic cigarette use, particularly for never users and dual users. These results suggested that older youth (those in the $12^{\text {th }}$ grade) were more likely to be dual users as compared to never users. These results are not consistent with the 2015 NYTS, which indicated a lack of grade-based discrepancies. However, these findings are consistent with other recent research which has suggested that being an older adolescent was significantly related to later use of conventional cigarettes among those who had ever tried an electronic cigarette (CDC, 2015; Wills et al., 2016). It is also interesting to note the similar findings between the current study and Wills and colleagues (2016), which had a significantly larger sample size $(n=2,338)$ as compared to the current study. Additionally, given that the study by Wills and colleagues was conducted exclusively in Hawaii, it interesting that results were similar across a distinct cultural and geographic area. Finally, it is also noteworthy that no significant differences were found based on grade level and electronic cigarette only use, which is consistent with the most recent NYTS. 
User group differences also were investigated as a function of family status (intact, single-parent, blended/other) and parental education, with results suggesting that youth from intact families were more likely to be never users as compared to electronic cigarette only or dual users. Inversely, youth from single-parent homes or blended/other family types were more likely to be electronic cigarette only or dual users as compared to never users. Similarly, in regards to parental education, results indicated that youth who had parents with a Bachelor's degree or above were more likely to be never users as compared to those who had parents with some college/specialized training or were a graduate of high school only. Among never users, no significant differences were found between youth with a mother who had a Bachelor's degree or above as compared to those with a mother who did not complete high school. However, in an interesting twist, results also suggested no significant patterns between maternal education level and electronic cigarette only use, suggesting that experimentation with electronic cigarettes may not be related to maternal education. In regards to dual use, though, results indicated that youth who have a mother that is a high school graduate only were most likely to be dual users of electronic and conventional cigarettes as compared to youth who had mothers that had a Bachelor's degree or above. Interesting group differences were also found based on comparisons between user group and paternal education. Like mothers, youth who had fathers with a Bachelor's degree were significantly more likely to be a never user as compared to youth with fathers of lower educational levels. Additionally, no significant differences existed (in regards to never use) between the three lower groups of paternal education (some college/vocational training and below) or between the higher groups of paternal education (Bachelor's degree and Master's degree or above), potentially suggesting that whether or not a father obtains a Bachelor's degree may be related to risk for experimentation with electronic cigarettes. 
However, at the same time, results also indicated no significant differences between use of electronic cigarettes and paternal education. It is important to note, however, that differences were found among dual users, such that youth who had fathers that were high school graduates were most likely to be dual users as compared to youth whose fathers had a Bachelor's degree or above. As such, these results may suggest that parental education (paternal and maternal education) may be more related to dual use or use of conventional cigarettes as compared to electronic cigarettes only, though more research is needed in this area.

Despite these interesting findings, family status and parental education have been somewhat neglected as potential covariates in recent studies. As such, further examination may be needed to confirm the potential of these variables to serve as covariates. It is also important to note in the current study that the sample was largely from intact families $(58.7 \%)$ and generally had high rates of parental education, with nearly $60 \%$ of mothers and nearly $54 \%$ of fathers reported as having a bachelor's degree or above. This is potentially the result of recruiting a considerable number of participants from a prominent college town within West Virginia.

\section{Relations Between Parent and Adolescent Strategies and User Group}

In examining parent behavior and information management strategies and adolescent information management strategies in relation to user group, results suggested significant differences between never users and the other two groups on most parent and youth strategies, except for parental solicitation and some slight discrepancy on parental behavioral control. To the researcher's knowledge, this is the first study examining the combination of these parent behavior and information management strategies and youth information management strategies in the context of electronic cigarette use. As such, further research is needed to confirm the accuracy of these findings. However, the current study can be compared with the conventional 
cigarette literature and the limited information currently available in the electronic cigarette literature.

As previously mentioned, though research on parenting factors and conventional cigarette use among youth has been mixed, some recent studies have suggested that parental behavioral control may serve a somewhat protective factor for conventional cigarette use. The current study would support this finding in regards to electronic cigarettes and conventional cigarettes as the average rating of parental behavioral control across the entire sample was relatively high. With that in mind, the majority of the sample also reported being a never user of electronic cigarettes. It is also interesting that the current results found significant differences between never users and dual users, as well as electronic cigarette users and dual users, on parental behavioral control never users and electronic cigarette users did not significantly differ. This finding may be the result of measuring lifetime only use of electronic cigarette use rather than also including current use (past 30 days). Our study did not have enough current users to assess these comparisons between current and lifetime users. As such, further research should explore the potential differences between current and lifetime only users, particularly on parental and youth behavior and information management strategies.

In regards to parental knowledge, youth disclosure, and youth secrecy, results similarly indicated significant differences between never users and both electronic cigarette only users and dual users. No significant differences were found between electronic cigarette only users and dual users on these variables, potentially due to the focus of the study on lifetime use only or the fact that these groups do not vary systematically (more research is needed to determine either possibility). It should be noted, however, that it is possible that we may come to find similar patterns of parenting and youth behavior and information management strategies across both the 
conventional and electronic cigarette literatures. Recent studies have shown initial support for this claim in finding that parenting factors, such as parental monitoring and knowledge, may serve a protective function against electronic cigarette use in similar ways as shown in adolescent conventional cigarette use (Wills et al., 2015). However, it should also be noted that more extensive research is needed to confirm or deny this possibility. Parental solicitation also was not found to be significantly different across user groups and the average rate of parental solicitation was found to be moderate in the current sample. While research on parental solicitation is also not very consistent, these findings do somewhat relate to research that has suggested that parental solicitation can have both positive and negative relations with adolescent delinquent behavior (e.g., Eaton, Krueger, Johnson, McGue, \& Iacono, 2009). As such, perhaps the moderate levels of parental solicitation across groups did not allow the data to show differences in support of one direction or the other.

\section{Secrecy-Driven Clusters and Adolescent Electronic Cigarette Usage}

Given the second and third aims of the study, the current examination also had the goal of creating profiles of parent and youth strategies and relating those strategies to electronic cigarette use. The current results suggested a two-cluster solution, predominately influenced by youth secrecy and disclosure. These findings suggest that while parenting behaviors and information management strategies do matter, as they may influence youth behavior, it is ultimately the youth's strategies that has the potential to have the strongest influence on lifetime use of electronic cigarette use.

The first cluster, referred to as the secretive cluster, were found to be more likely to have parents that were less behaviorally controlling, less likely to solicit information from the adolescent, and be less knowledgeable overall of the youth's activities. Additionally, as 
expected, these youths were also less likely to disclose information about their activities and whereabouts. The second cluster, referred to as the less secretive cluster, resulted in an opposing profile, where parents were more likely to engage in some behavioral control, solicitation of information, and have some knowledge regarding the adolescent's activities. These adolescents were also more likely to disclose information to their parents. Interestingly, while youth secrecy was drastically high or low (depending on the cluster), youth disclosure and the parent behavior and information management strategies were relatively similar (moderately high or low, depending on the cluster). These findings also provide evidence of the potential bidirectionality between parent and youth behaviors. As such, it is possible that youth disclosure is moderately positive in the less secretive cluster, thereby related to moderate parental knowledge. Likewise, moderate parental solicitation may, in turn, relate to moderate disclosure by the youth.

Though at first sight these results appear intuitive, the current study has provided important information about the power of youth secrecy above and beyond other parenting factors and youth disclosure. Given that youth secrecy was high in one cluster and low in the other, it would be reasonable to expect youth disclosure to have a similar, though opposite, effect. However, while youth disclosure did trend in the expected direction (more disclosure in the less secretive cluster and less disclosure in the more secretive group), the difference between disclosure in each cluster was not as large as with youth secrecy. This is consistent with prior evidence suggesting that disclosure and secrecy are only moderately inversely correlated (Smetana, Metzger, Gettman, \& Campione-Barr, 2006). The present study also provides somewhat converging evidence with other studies (e.g., Metzger et al., 2013) that consider the incremental utility of considering what an adolescent keeps secrets about in trying to determine who is likely to engage in smoking behaviors. As is consistent with this statement, results from 
the cluster analysis indicated that electronic cigarette only users and dual users were more likely to fall in the secretive cluster than in the less secretive cluster.

In assessing these cluster-based aims, results also indicated significant differences in gender between clusters, such that females were more likely to fall in the less secretive cluster. This is consistent with prior research that suggests that adolescent males are more likely to engage in secrecy and less likely to engage in disclosure than adolescent females (Keijsers et al., 2010).

\section{Limitations and Future Directions}

Findings from the current study should be interpreted in light of the limitations it possesses. First, given the potential impacts of social desirability effects, there is the possibility that youth under-reported their behavior or reports of parenting behavior. That being said, rates of electronic cigarette use were found to be consistent with other recent studies and measures were taken to diminish the effects of social desirability, such as encouraging parents to sit away from youth while completing measures in the clinic setting and making the packets completely de-identified. An additional limitation of the current study is the potential bias of youth reports on parenting behaviors. While it would have been ideal to have parent reports in which to contrast with youth report, this was unfeasible for the nature of the current study (e.g., schoolbased recruitment). Additionally, the current study was crafted within the constraints of the ongoing dissertation project from which it was inspired. Third, recent research has suggested the impact of race on parenting behaviors as well as youth engagement in problem behaviors. Due to a lack of variability in race, differences were not found in the current study and could not be analyzed to the extent that other studies have investigated. As such, further research is needed to determine if race may play a significant role in determining cluster assignment. Fourth, the current study was only able to determine a two-cluster solution. While more clusters may have 
been able to provide more qualitative description and more nuanced differences between profiles, the current study is still important in providing initial evidence for the potential of bidirectional relations between parent and youth behavior as well as between those behaviors and adolescent electronic cigarette use. Fifth, in regards to youth disclosure and secrecy, while these factors appear to be important in creating profiles of adolescent electronic cigarette users, patterns of youth disclosure and secrecy are complex and often nuanced. A large survey-based study of this nature is not able to assess varying levels of types of disclosure and secrecy (e.g., active secrecy/lying versus withholding information) to the extent that they should be examined. Related to these concerns, internal consistency for the parental knowledge measure and the youth disclosure scale were areas of concern for the current study, potentially impacting results. As such, further examination and research with these measures, particularly in comparison with other measures of the same construct, should be pursued in future studies. Sixth, given the infancy of this research in the electronic cigarette literature, the study was exploratory in nature. It is entirely possible that additional parenting or youth behaviors may lead to changes in current profiles or yield additional profiles for adolescents who use electronic cigarettes. Nonetheless, to ensure power, the current study limited its scope to specific youth and parenting strategies. However, additional information may be gleamed from the examination of related variables, such as parent-adolescent communication and conflict. In addition, families were primarily intact and parents were highly educated compared to the general population. As such, it is possible that this sample may differ from the general population, particularly on parent behaviors and strategies. Future studies should be conducted with more representative samples to address these concerns. 
Despite these limitations, the current study has many strengths, particularly in its novelty and contribution to the electronic cigarette literature. Few studies to date have assessed parent and youth behavioral and information management strategies within the electronic cigarette literature and the current study is the first to examine a more extensive compilation of adolescent and parenting strategies. Additionally, very few studies in the electronic cigarette literature have utilized advanced, multivariate analytic techniques, such as a cluster analysis. The current study also takes a profile-based approach to these factors in relation to electronic cigarette use, which has yet to be conducted in the literature. Finally, the current study also includes standardized measures with only slight adaptations (e.g., addition of one or two questions). Other studies have not used standardized measures of parenting behaviors (e.g., Wills et al., 2015) to assess constructs of interest. A lack of demonstrated psychometric properties for measures can reduce a researcher's confidence in the accuracy of results and study conclusions.

In all, the current study took a novel approach to characterizing groups of adolescent electronic cigarette users. The results suggest that further examination of the bidirectional relation between parent and youth behavioral and information management strategies is needed within the context of adolescent electronic cigarette use and dual use of electronic cigarettes and conventional cigarettes. Results from the current study as well as future research stemming from this project provide support for the Surgeon General's 2015 calls for parental involvement in reducing electronic cigarette use as well as assist in the development of public policy and preventative efforts. For example, given the power of adolescent secrecy as demonstrated in the current study, preventative strategies may wish to focus on ways to encourage youth disclosure and honesty as well as methods of communication between adolescents and parents that encourage these behaviors. The current study has also provided initial evidence that moderate 
levels of parental behavioral control, solicitation, and knowledge may serve a protective function for adolescent secrecy and adolescent use of electronic cigarettes. As such, if research in this area continues to show these relations, new initiatives for parental education could be the result. In particular, these efforts may focus on specific strategies (e.g., rule setting, balancing youth autonomy with parental knowledge and solicitation) to discourage adolescent access to and use of electronic cigarettes.

\section{Dissemination of Research Findings}

To ensure results from this study will be utilized and further research directions are pursued, the information from the current study will be disseminated via poster presentations at academic conference and publications in scientific journals with the intention of reaching a large, interdisciplinary audience of researchers (e.g., psychology, public health and policy, tobacco and nicotine groups). In addition, research findings will also be disseminated into the community via school-based presentations aimed at educating both youth and teachers about electronic cigarette use specific to their school and surrounding communities. 


\section{References}

Bergman, L. R., Magnusson, D., \& El Khouri, B. M. (2003). Studying individual development in an interindividual context: A person-oriented approach. (Vols. 1-4). Mahwah, NJ: Lawrence Erlbaum Associates Incorporated.

Bertholon, J.F., Becquemin, M.H., Annesi-Maesano, I., Dautenzberg, B. (2013). Electronic cigarettes: A short review. Respiration, 86, 433-438.

Brown, C. J., \& Cheng, J. M. (2014). Electronic cigarettes: Product characterisation and design considerations. Tobacco Control, 23(suppl 2), ii4-ii10.

Brener, N. D., Collins, J. L., Kann, L., Warren, C. W., \& Williams, B. I. (1995). Reliability of the youth risk behavior survey questionnaire. American Journal of Epidemiology, 141(6), 575-580.

Brener, N. R., Kann, L., McManus, T., Kinchen, S. A., Sundberg, E. C., \& Ross, J. G. (2002). Reliability of the 1999 youth risk behavior survey questionnaire. Journal of Adolescent Health, 31(4), 336-342.

Camenga, D. R., Delmerico, J., Kong, G., Cavallo, D., Hyland, A., Cummings, K. M., \& Krishnan-Sarin, S. (2014). Trends in use of electronic nicotine delivery systems by adolescents. Addictive Behaviors, 39(1), 338-340. doi:10.1016/j.addbeh.2013.09.014

Centers for Disease Control and Prevention (1994). Preventing tobacco use among young people: A report of the surgeon general (Executive Summary). Morbidity and Mortality Weekly Report, 43(4), 1-24.

Centers for Disease Control and Prevention (2010). Cigarette use among high school students United states, 1991-2009. Morbidity and Mortality Weekly Report, 59(26), 797-801. 
Centers for Disease Control and Prevention (2012a). Monitoring your teen's activities: What parents and families should know. Retrieved from https://www.cdc.gov/healthyyouth/protective/pdf/parental_monitoring_factsheet.pdf.

Centers for Disease Control and Prevention (2012b). Preventing tobacco use among youth and young adults: A report from the surgeon general. Retrieved from https://www.surgeongeneral.gov/library/reports/preventing-youth-tobacco-use/.

Centers for Disease Control and Prevention (2013). Notes from the field: Electronic cigarette use among middle and high school students -United States, 2011-2012. Morbidity and Mortality Weekly Report, 62(35), 729-730.

Centers for Disease Control and Prevention (2015a). Tobacco use among middle and high school students: United states, 2011-2014. Morbidity and Mortality Weekly Report, 64(14), 381385.

Centers for Disease Control and Prevention (2015b) Youth Risk Behavior Survey. Available at: www.cdc.gov/yrbs. Accessed on December 30, 2015.

de Andrade, M., Hastings, G., \& Angus, K. (2013). Promotion of electronic cigarettes: Tobacco marketing reinvented? British Medical Journal, 347, f7473.

DiClemente, R. J., Hansen, W. B., \& Ponton, L. E. (Eds.). (2013). Handbook of adolescent health risk behavior. New York, NY: Springer Science \& Business Media.

Duke, J. C., Lee, Y. O., Kim, A. E., Watson, K. A., Arnold, K. Y., Nonnemaker, J. M., \& Porter, L. Exposure to electronic cigarette television advertisements among youth and young adults. Pediatrics, 134(1), e29-e36. doi:10.1542/peds.2014-0269 
Delucchi, K. L. (1993). On the use and misuse of chisquare. In G. Keren \& C. Lewis (Eds.), A handbook for data analysis in the behavioral sciences (pp. 294- 319). Hillsdale, NJ: Lawrence Erlbaum.

Dutra, L. M. \& Glanz, S. A. (2014). E-cigarettes and conventional cigarette use among U.S. adolescents: A cross-sectional study. JAMA Pediatrics, 168(7), 610-617.

Eaton N. R. , Krueger R. F., Johnson W., McGue, M., \& Iacono, W. G. (2009). Parental monitoring, personality, and delinquency: Further support for a reconceptualization of monitoring. Journal of Research in Personality, 43, 49-59. doi: 10.1016/j.jrp.2008.10.006

Farsalinos, K. E., Romagna, G,, Tsiapras, D., Kyrzopoulos, S., Spyrou, A., \& Voudris, V. (2013). Impact of flavour variability on electronic cigarette use experience: An internet survey. International Journal of Environmental Research and Public Health, 10(12), 7272-7278. doi: $10.3390 /$ ijerph10127272

Field, A. (2013). Discovering statistics using IBM SPSS statistics. New Delhi, IN: Sage Publications India.

Fletcher, A. C., Steinberg, L., \& Williams-Wheeler, M. (2004). Parental influences on adolescent problem behavior: Revisiting Stattin and Kerr. Child Development, 75(3), 781-796.

Grana, R., Benowitz, N., \& Glantz, S. A. (2014). E-cigarettes: A scientific review. Circulation, 129, 1972-1986.

Hair, J. F., Black, W. C., Babin, B. J., Anderson, R. E., \& Tatham, R. L. (2006). Multivariate data analysis (Vol. 6). Upper Saddle River, NJ: Pearson Prentice Hall.

Hua, M., Alfi, M., \& Talbot, P. (2013). Health-related effects reported by electronic cigarette 
users in online forums. Journal of Medical Internet Research, 15(4).

doi:10.2196/jmir.2324

Hajek, P., Etter, J. F., Benowitz, N., Eissenberg, T., \& McRobbie, H. (2014). Electronic cigarettes: Review of use, content, safety, effects on smokers and potential harm and benefit. Addiction, 109(11), 1801-1810.

Harakeh, Z., Scholte, R. H. J., de Vries, H., \& Engels, R. C. M. E. (2005). Parental rules and communication: Their association with adolescent smoking. Addiction, 100(6), 862-870.

Hawk, S. T., Jansen, E., \& Jellesma, F. (2012). Does wanting privacy mean you have something to hide? Early-adolescents distinctions between privacy and secrecy. Poster presented at the biennial meeting of the European Association for Research on Adolescence, Spetses, Greece.

Jensen, C. D., Cushing, C. C., Aylward, B. S., Craig, J. T., Sorell, D. M., \& Steele, R. G. (2011). Effectiveness of motivational interviewing interventions for adolescent substance use behavior change: A meta-analytic review. Journal of Consulting and Clinical Psychology, 79(4), 433.

Goniewicz, M. L., \& Zielinska-Danch, W. (2012). Electronic cigarette use among teenagers and young adults in Poland. Pediatrics, 130(4), e879-e885. doi:10.1542/peds.2011-3448

Goniewicz, M. L., Kuma, T., Gawron, M., Knysak, J., \& Kosmider, L. (2013). Nicotine levels in electronic cigarettes. Nicotine \& Tobacco Research, 15(1), 158-166.

Kann, L., McManus, T., Harris, W. A., Shanklin, S. L., Flint, K. H., Hawkins, J., ... Zaza, S. (2016). Youth Risk Behavior Surveillance - United States, 2015. Morbidity and Mortality 
Weekly Report. Surveillance Summaries (Washington, D.C. : 2002), 65(6), 1-174. http://doi.org/10.15585/mmwr.ss6506a1

Keijsers, L., Frijns, T., Branje, S. J. T., \& Meeus, W. (2009). Developmental links of adolescent disclosure, parental solicitation, and control with delinquency: Moderation by parental support. Developmental Psychology, 45, 1314-1327. doi: 10.1037/a0016693.

Keijsers, L., Branje, S. J. T., VanderValk, I. E., \& Meeus, W. (2010). Reciprocal effects between parental solicitation, parental control, adolescent disclosure, and adolescent delinquency. Journal of Research on Adolescence, 20, 88-113. doi:10.111/j.1532-7795. 2009.00631.x.

Kerr, M., \& Stattin, H. (2000). What parents know, how they know it, and several forms of adolescent adjustment: Further support for a reinterpretation of monitoring. Developmental Psychology, 36, 366-380. doi:10.1037/0012-1649.36.3.366.

Kerr, M., Stattin, H., \& Burk, W. J. (2010). A reinterpretation of parental monitoring in longitudinal perspective. Journal of Research on Adolescence, 20, 39-64. doi: 10.1111/j.1532-7795.2009.00623.x.

Kerr, M., Stattin, H., \& Özdemir, M. (2012). Perceived parenting style and adolescent adjustment: Revisiting directions of effects and the role of parental knowledge. Developmental Psychology, 48(6), 1540-1553.

Kong, G., Morean, M. E., Cavallo, D. A., Camenga, D. R., \& Krishnan-Sarin, S. (2015). Reasons for electronic cigarette experimentation and discontinuation among adolescents and young adults. Nicotine and Tobacco Research, 17(7), 847-854. doi: 10.1093/ntr/ntu257

Lamborn, S.D., Mounts, N.S., Steinberg, L., \& Dornbusch, S. M. (1991). Patterns of competence and adjustment among adolescents from authoritative, authoritatian, indulgent, and neglectful families. Child Development, 62, 1049-1065.doi:10.2307/1131151. 
Liao, Y., Huang, Z., Huh, J., Pentz, M. A., \& Chou, C.P. (2013). Changes in friends' and parental influences on cigarette smoking from early through late adolescence. Journal of Adolescent Health, 53(1), 132-138. doi: 10.1016/j.jadohealth.2013.01.020

Mahabee-Gittens, E. M., Xiao, Y., Gordon, J. S., \& Khoury, J. C. (2013). The dynamic role of parental influences in preventing adolescent smoking initiation. Addictive behaviors, 38(4), 1905-1911.

Metzger, A., Wakschlag, L. S., Anderson, R., Darfler, A., Price, J., Flores, Z., \& Mermelstein, R. (2013). Information management strategies within conversations about cigarette smoking: Parenting correlates and longitudinal associations with teen smoking. Developmental psychology, 49(8), 1565-1578. doi: 10.1037/a0030720

Moreno, M. A. (2014). Electronic cigarettes. JAMA Pediatric, 168(7), 688. doi: 10.1001/jamapediatrics.2013.3355.

National Institutes of Health (2010 May 13). Propylene Gycol. Retrieved from http://toxnet.nlm.nih.gov/cgi-bin/sis/search/a?dbs+hsdb:@term+@DOCNO+174

National Institutes of Health (2011 September 22). Glyerin. Retrieved from http://toxnet.nlm.nih.gov/cgi-bin/sis/searh/a?dbs+hsdb:@term+@DOCNO+492.

North Dakota Department of Health. Tobacco Prevention and Control Program (2015, January). Tobacco facts: Electronic cigarettes (e-cigarettes). Retrieved from https://www.ndhealth.gov/tobacco/Facts/E-cigs.pdf.

Owusu, D., Aibangbee, J., Collins, C., Robertson, C., Wang, L., Littleton, M., Boghozian, R., Casenburg, V., \& Mamudu, H. M. (2016). The use of electronic cigarettes among schoolgoing adolescents in a predominately rural environment of central Appalachia. Journal of Community Health. doi: 10.1007/s10900-016-0297-0 
Palazzolo, D. L. (2013). Electronic cigarettes and vaping: A new challenge in clinical medicine and public health. A literature review. Frontiers in Public Health, 1(56). Retrieved from http://www.ncbi.nlm.nih.gov/pmc/articles/PMC3859972.

Pentz, M. A. \& Riggs, N. R. (2013). Longitudinal relationships of executive cognitive function and parent influence to child substance use and physical activity. Prevention Science, 14(3). 229-237.

Pentz, M. A., Shin, H., Riggs, N., Unger, J. B., Collison, K. L., \& Chou, C.-P. (2015). Parent, peer, and executive function relationships to early adolescent e-cigarette use: A substance use pathway? Addictive Behaviors, 42, 73-78. doi:10.1016/j.addbeh.2014.10.040

Perrin, J. M. (2014). Two child health threats in the news: e-cigarettes, rising autism rates. American Academy of Pediatric News, 35(5), 6.

Protano, C., Di Milia, L. M., Orsi, G. B., \& Vitali, M. (2015). Electronic cigarette: a threat or an opportunity for public health? State of the art and future perspectives. Clinical Therapeutics, 166(1), 32-37.

Rigotti, N. A. (2015). e-Cigarette use and subsequent tobacco use by adolescents: New evidence about a potential risk of e-cigarettes. Journal of the American Medical Association, $314(7), 673-674$.

Robin, A. L., \& Foster, S. L. (1995). The conflict behavior questionnaire. In M. Hersen \& A. S. Bellack (Eds.), Dictionary of Behavorial Techniques (pp. 148-150). New York, NY: Pergamon.

Smetana, J. G., Metzger, A., Gettman, D. C., \& Campione-Barr, N. (2006). Disclosure and secrecy and adolescent-parent relationships. Child Development, 77(1), 201-217. doi: 10.1111/j.1467-8624.2006.00865.x 
Smetana, J. G., Villalobos, M., Tasopoulos-Chan, M., Gettman, D. C., Campione-Barr, N. (2009). Early and middle adolescents' disclosure to parents about activities in different domains. Journal of Adolescence, 32(3), 693-713. doi:10.1016/j.adolescence.2008.06.010

Stattin, H. \& Kerr, M. (2000). Parental monitoring: A reinterpretation. Child Development, 71, 1070-1083.

Tilton-Weaver, L. Adolescents' information management: Comparing ideas about why adolescents disclose to or keep secrets from their parents. Journal of Youth \& Adolescence, 43, 803-813. doi: 10.1007/s10964-013-0008-4

U.S. Census Bureau (2015, February 9). Urban and Rural Classification. Retrieved from https://www.census.gov/geo/reference/urban-rural.html.

U.S. Department of Health and Human Services (DHHS) (2012). Preventing tobacco use among youth and young adults: A report of the surgeon general (Executive Summary). Retrieved from http://www.cdc.gov/tobacco/data_statistics/sgr/2012/index.htm.

U.S. Department of Health and Human Services (DHHS) (2012). Preventing tobacco use among young adults: A report of the surgeon general. Retrieved from http://www.ncbi.nlm.nih.gov/books/NBK99237/.

U.S. Department of Health and Human Services (DHHS) (2014). The health consequences of smoking - 50 years of progress: A report of the surgeon general. Retrieved from http://www.cdc.gov/tobacco/data_statistics/sgr/50th-anniversary/index.htm.

U.S. Department of Health and Human Services (DHHS) (2016). E-cigarette use among youth and young adults: A report of the surgeon general. Retrieved from https://ecigarettes.surgeongeneral.gov/takeaction.html. 
Vardavas, C. I., Anagnostopoulos, N., Kougias, M., Evangelopoulou, V., Connolly, G. N., \& Behrakis, P. K. (2012). Short-term pulmonary effects of using an electronic cigarette: Impact on respiratory flow resistance, impedance, and exhaled nitric oxide. Chest, 141, 1400-1406. doi:10.1378/chest.11-2443.

Vieno, A., Nation, M., Pastore, M., \& Santinello, M. (2009). Parenting and antisocial behavior: A model of the relationship between adolescent self-disclosure, parental closeness, parental control, and adolescent antisocial behavior. Developmental Psychology, 45(6), 1509.

Williams, M., Villarreal, A., Bozhilov, K., Lin, S., Talbot, P. (2013). Metal and silicate particles including nanoparticles are present in electronic cigarette cartomizer fluid and aerosol. PLoS ONE 8(3), e57987. doi:10.1371/journal.pone.0057987.

Wills, T. A., Knight, R., Williams, R. J., Pagano, I., \& Sargent, J. D. (2015). Risk factors for exclusive e-cigarette use and dual e-cigarette use and tobacco use in adolescents. Pediatrics, 135(1), e43-e51. doi:10.1542/peds.2014-0760.

Yuan, M., Cross, S. J., Loughlin, S. E., \& Leslie, F. M. (2015). Nicotine and the adolescent brain. Journal of Physiology, 593(pt 16), 3397-3412.

Zhu, S. H., Sun, J. Y., Bonnevie, E., Cummins, S. E., Gamst, A., Yin, L., \& Lee, M. (2014). Four hundred and sixty brands of e-cigarettes and counting: Implications for product regulation. Tobacco Control, 23(suppl 3), iii3-iii9. 
Table 1

Coding of Variables Used in Analyses

\begin{tabular}{|c|c|c|}
\hline Variable & Coding & Measure Taken From \\
\hline Gender & $\begin{array}{l}1=\text { Male } \\
2=\text { Female }\end{array}$ & SIF \\
\hline Race & $\begin{array}{l}1=\text { Caucasian } \\
2=\text { Minority }\end{array}$ & SIF \\
\hline Grade/Year in School & $\begin{array}{l}9=\text { Freshman } \\
10=\text { Sophomore } \\
11=\text { Junior } \\
12=\text { Senior }\end{array}$ & SIF \\
\hline Recruitment site & $\begin{array}{l}1=\text { High school } \\
2=\text { Adolescent clinic }\end{array}$ & SIF \\
\hline Family Status & $\begin{array}{l}1=\text { Intact } \\
2=\text { Single parent } \\
3=\text { Blended/Other }\end{array}$ & SIF \\
\hline $\begin{array}{l}\text { Parent Education } \\
\text { (Mother and Father) }\end{array}$ & $\begin{array}{l}0=\text { Less than high school graduate } \\
1=\text { High school graduate } \\
2=\text { Some college or specialized training } \\
3=\text { Bachelor's degree } \\
4=\text { Master's degree or doctoral degree }\end{array}$ & SIF \\
\hline $\begin{array}{l}\text { Electronic Cigarette Use } \\
\text { (User Group) }\end{array}$ & $\begin{array}{l}0=\text { Never user } \\
1=\text { Electronic cigarette only user } \\
2=\text { Dual user }\end{array}$ & SIF \\
\hline $\begin{array}{l}\text { Parental Behavioral } \\
\text { Control }\end{array}$ & Higher values $=$ Greater behavioral control & PBC \\
\hline Parental Knowledge & Higher values $=$ Greater parental knowledge & PKM \\
\hline Parental Solicitation & Higher values $=$ Greater parental solicitation & PSM \\
\hline Youth Disclosure & Higher values $=$ Greater youth disclosure & YDS-D \\
\hline Youth Secrecy & Higher values = Greater youth secrecy & YDS-S \\
\hline
\end{tabular}


Table 2

Participant Demographics and Frequencies

\begin{tabular}{|c|c|c|}
\hline Variables $(N=562)$ & & $\mathrm{M}(\mathrm{SD}) / \mathrm{n}(\%)$ \\
\hline Age & & $15.95(1.16)$ \\
\hline \multirow[t]{2}{*}{ Gender } & Male & $228(40.6 \%)$ \\
\hline & Female & $333(59.3 \%)$ \\
\hline \multirow[t]{2}{*}{ Race } & Caucasian & $467(83.1 \%)$ \\
\hline & Minority & $88(15.7 \%)$ \\
\hline \multirow[t]{4}{*}{ Grade/Year in School } & Freshman & $71(12.7 \%)$ \\
\hline & Sophomore & $204(36.4 \%)$ \\
\hline & Junior & $170(30.2 \%)$ \\
\hline & Senior & $116(20.6 \%)$ \\
\hline \multirow[t]{2}{*}{ Recruitment site } & High school & $508(90.4 \%)$ \\
\hline & Adolescent clinic & $52(9.3 \%)$ \\
\hline \multirow[t]{3}{*}{ Family Status } & Intact & $330(58.7 \%)$ \\
\hline & Single & $110(19.6 \%)$ \\
\hline & Blended/Other & $122(21.7 \%)$ \\
\hline \multirow[t]{5}{*}{ Maternal Education } & Less than high school degree & $21(3.7 \%)$ \\
\hline & High school graduate & $85(15.1 \%)$ \\
\hline & Some college or specialized training & $117(20.8 \%)$ \\
\hline & Bachelor's degree & $219(39.0 \%)$ \\
\hline & Master's degree or doctoral degree & $107(19.0 \%)$ \\
\hline \multirow[t]{5}{*}{ Paternal Education } & Less than high school degree & $25(4.4 \%)$ \\
\hline & High school graduate & $122(21.7 \%)$ \\
\hline & Some college or specialized training & $98(17.4 \%)$ \\
\hline & Bachelor's degree & $154(27.4 \%)$ \\
\hline & Master's degree or doctoral degree & $133(23.7 \%)$ \\
\hline Electronic Cigarette & Never user & $319(56.8 \%)$ \\
\hline \multirow[t]{2}{*}{ Use (User Group) } & Electronic cigarette only user & $94(16.7 \%)$ \\
\hline & Dual user & $125(22.2 \%)$ \\
\hline
\end{tabular}


Table 3

Descriptive Statistics

\begin{tabular}{lrrrr}
\hline & Mean & SD & Min & Max \\
\hline Parental Behavioral Control & 4.08 & .93 & 1.00 & 5.00 \\
Parental Knowledge & 3.04 & .53 & 1.00 & 5.00 \\
Parental Solicitation & 2.74 & .73 & 1.00 & 5.00 \\
Youth Disclosure & 2.56 & .69 & 1.00 & 5.00 \\
Youth Secrecy & 1.98 & 1.13 & 1.00 & 5.00 \\
& & & & \\
\hline
\end{tabular}

Note: Higher values indicate higher levels of each respective construct (range $=1$ to 5 ). 
Table 4

Skew and Kurtosis Information for Outcome Variables

\begin{tabular}{|c|c|c|c|c|c|c|}
\hline & Skew & $\begin{array}{r}\text { Standard } \\
\text { Error } \\
\end{array}$ & zSkew & Kurtosis & $\begin{array}{r}\text { Standard } \\
\text { Error } \\
\end{array}$ & zKurtosis \\
\hline \multicolumn{7}{|l|}{ Original Data } \\
\hline Parental Behavioral Control & -1.02 & 0.10 & -9.87 & 0.54 & 0.21 & 2.61 \\
\hline Parental Knowledge & 0.30 & 0.10 & 2.92 & 2.32 & 0.21 & 11.28 \\
\hline Parental Solicitation & -0.17 & 0.10 & -1.65 & -0.20 & 0.21 & -0.97 \\
\hline Youth Disclosure & 0.21 & 0.10 & 1.99 & 0.76 & 0.21 & 3.70 \\
\hline Youth Secrecy & 0.84 & 0.10 & 8.12 & -0.11 & 0.21 & -0.52 \\
\hline \multicolumn{7}{|l|}{ Square Root Transformations } \\
\hline Parental Behavioral Control & -1.41 & 0.10 & -13.67 & 2.112 & 0.21 & 10.25 \\
\hline Parental Knowledge & -0.28 & 0.10 & -2.69 & 2.769 & 0.21 & 13.44 \\
\hline Parental Solicitation & -0.58 & 0.10 & -5.58 & 0.294 & 0.21 & 1.43 \\
\hline Youth Disclosure & -0.37 & 0.10 & -3.52 & 0.919 & 0.21 & 4.46 \\
\hline \multicolumn{7}{|l|}{ Logarithmic Transformations } \\
\hline Parental Behavioral Control & -1.97 & 0.10 & -19.08 & 5.05 & 0.21 & 24.53 \\
\hline Parental Knowledge & -0.97 & 0.10 & -9.44 & 4.93 & 0.21 & 23.95 \\
\hline Parental Solicitation & -1.05 & 0.10 & -10.18 & 1.44 & 0.21 & 6.99 \\
\hline Youth Disclosure & -1.03 & 0.10 & -10.03 & 2.54 & 0.21 & 12.33 \\
\hline Youth Secrecy & -0.10 & 0.10 & -0.92 & -0.88 & 0.21 & -4.28 \\
\hline
\end{tabular}

Note: Bolded items indicate violations of the normality assumption. 
Table 5

Current Use of Electronic Cigarettes among Electronic Cigarette Only Users and Dual Users $(N=219)$

\begin{tabular}{ccc}
\hline \# of Days Youth Used an E-cigarette & Frequency & Percent \\
\hline 0 days & 119 & $53.6 \%$ \\
1-2 days & 49 & $22.1 \%$ \\
3-5 days & 14 & $6.3 \%$ \\
6-9 days & 13 & $5.9 \%$ \\
10-19 days & 11 & $5.0 \%$ \\
20-29 days & 3 & $1.4 \%$ \\
All 30 days & 10 & $4.6 \%$
\end{tabular}

Note: Current use is defined as the use of an electronic cigarette within the past 30 days. 
Table 6

Games-Howell Post-Hoc Analyses for Aim 1

95\% Confidence Interval

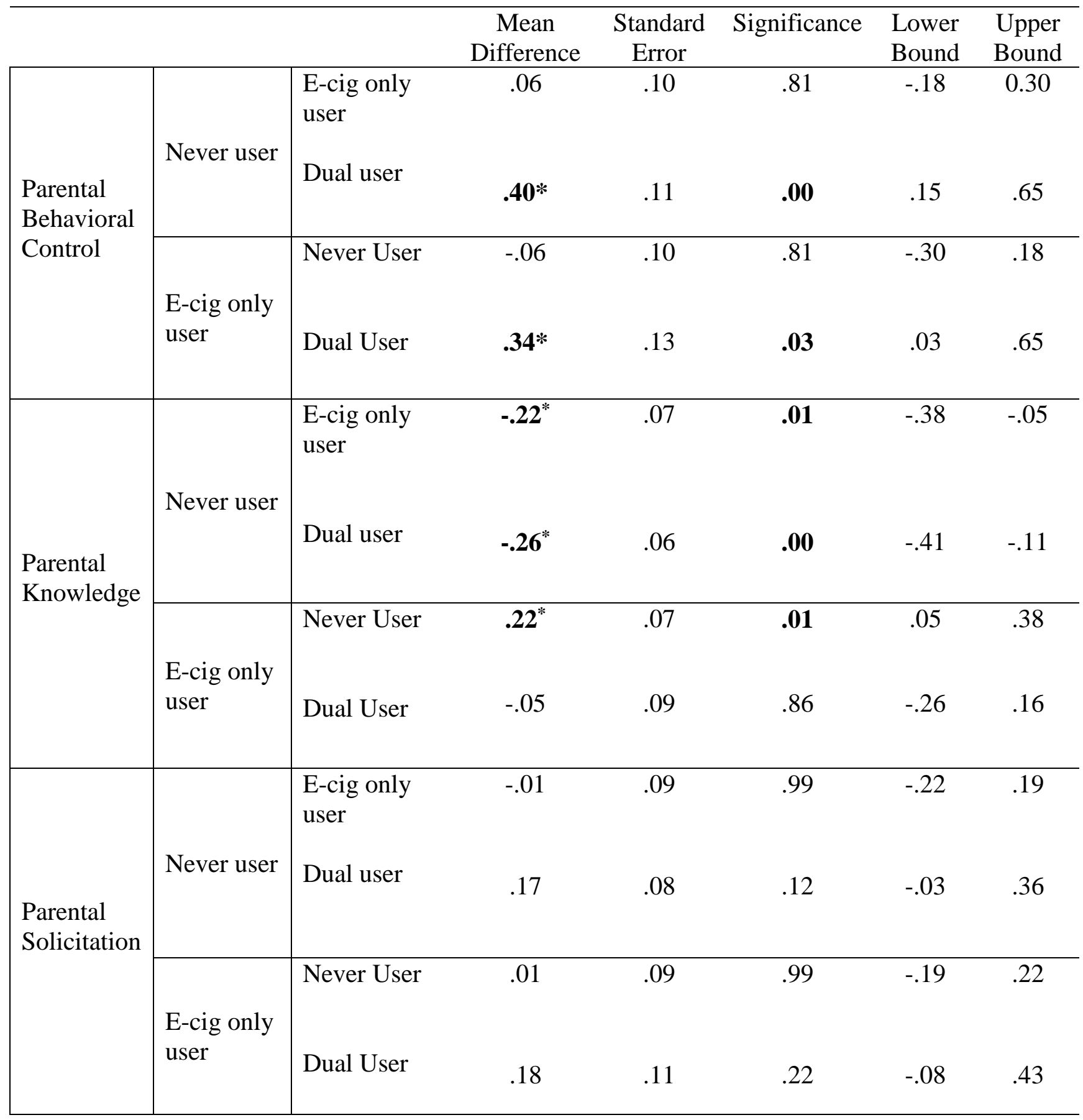

Note: $*$ The mean difference is significant at the .05 level. 
Table 6 Continued

Games-Howell Post-Hoc Analyses for Aim 1

95\% Confidence Interval

\begin{tabular}{|c|c|c|c|c|c|c|c|}
\hline & & & $\begin{array}{c}\text { Mean } \\
\text { Difference }\end{array}$ & $\begin{array}{c}\text { Standard } \\
\text { Error }\end{array}$ & Significance & $\begin{array}{l}\text { Lower } \\
\text { Bound }\end{array}$ & $\begin{array}{l}\text { Upper } \\
\text { Bound } \\
\end{array}$ \\
\hline \multirow{2}{*}{$\begin{array}{l}\text { Youth } \\
\text { Disclosure }\end{array}$} & Never user & $\begin{array}{l}\text { E-cig only } \\
\text { user } \\
\text { Dual user }\end{array}$ & $\begin{array}{l}-.25^{*} \\
-.21^{*}\end{array}$ & .08 & $\begin{array}{l}.02 \\
.02\end{array}$ & $\begin{array}{r}-.47 \\
-.39\end{array}$ & $\begin{array}{l}-.03 \\
-.02\end{array}$ \\
\hline & $\begin{array}{l}\text { E-cig only } \\
\text { user }\end{array}$ & $\begin{array}{l}\text { Never User } \\
\text { Dual User }\end{array}$ & $\begin{array}{l}.25^{*} \\
.04\end{array}$ & .09 & .02 & .03 & .47 \\
\hline \multirow{2}{*}{$\begin{array}{l}\text { Youth } \\
\text { Secrecy }\end{array}$} & Never user & $\begin{array}{l}\text { E-cig only } \\
\text { user } \\
\text { Dual user }\end{array}$ & $-1.43^{*}$ & 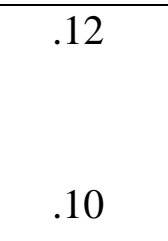 & 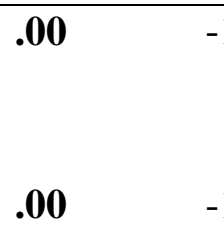 & . & -1.14 \\
\hline & $\begin{array}{l}\text { E-cig only } \\
\text { user }\end{array}$ & Never user & $1.43 *$ & .12 & .00 & 1379 & 1.72 \\
\hline
\end{tabular}

Note: $*=$ The mean difference is significant at the .05 level. 


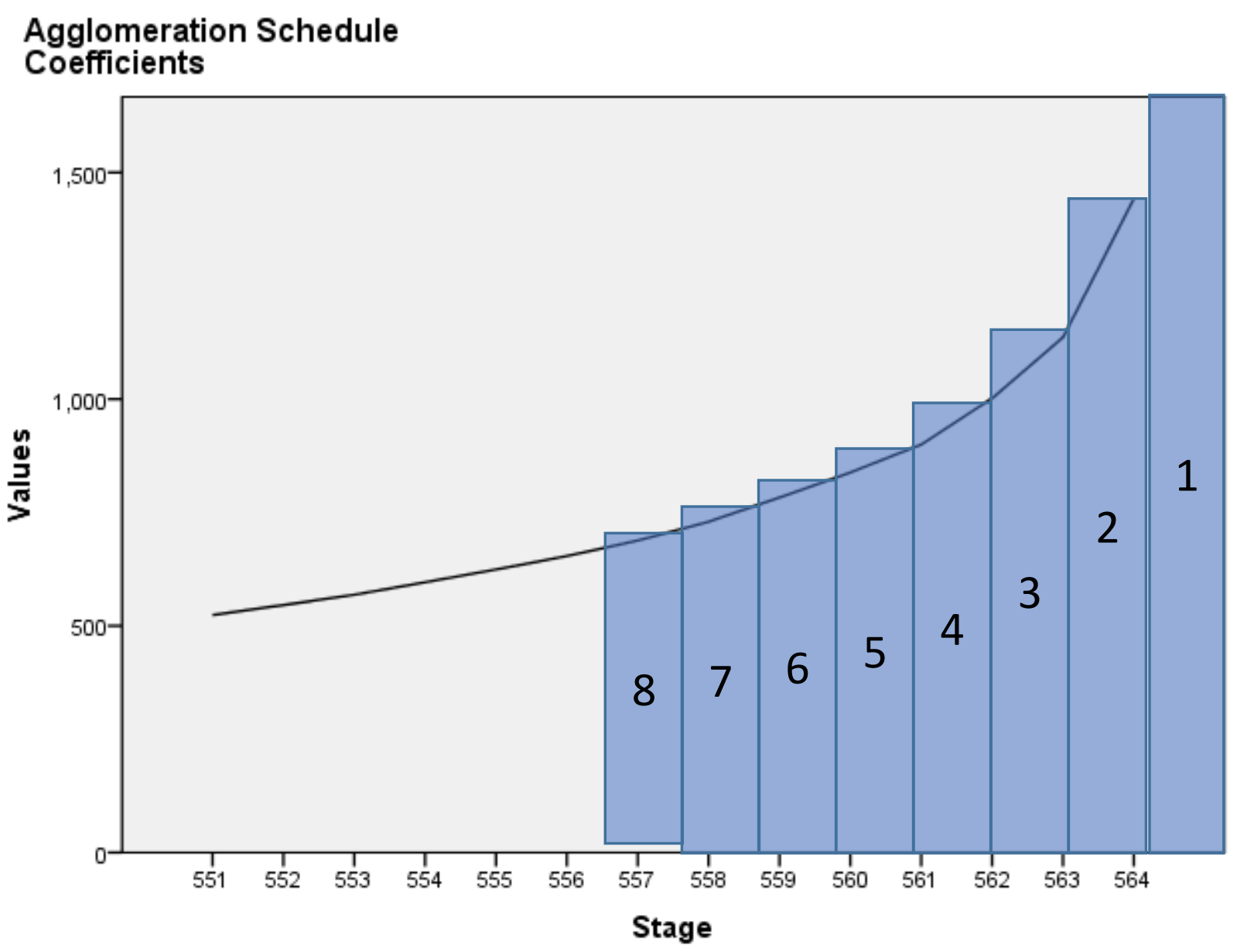

Figure 1. Agglomeration Schedule. 


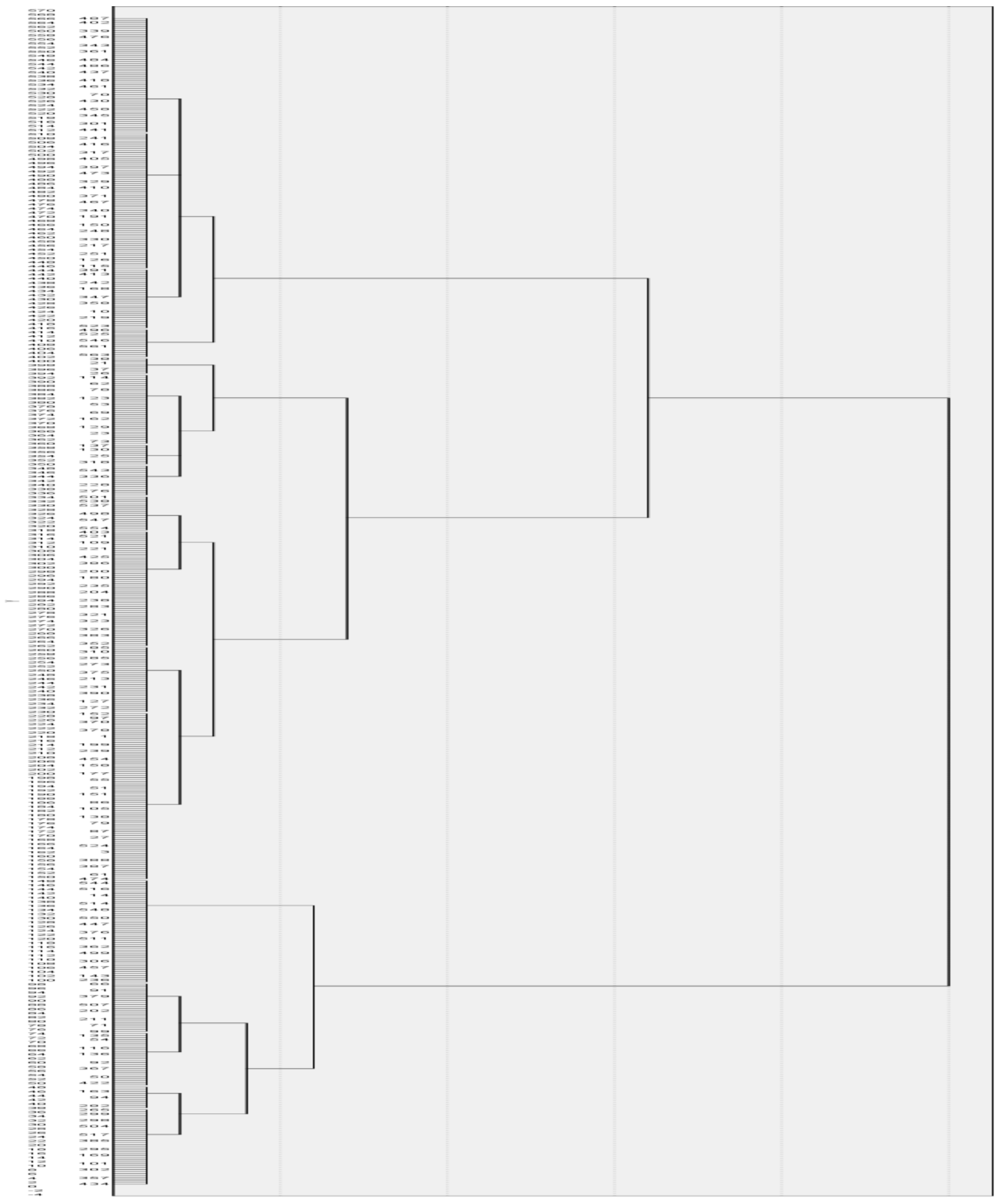

Figure 2. Dendrogram Utilizing Ward Linkage. 


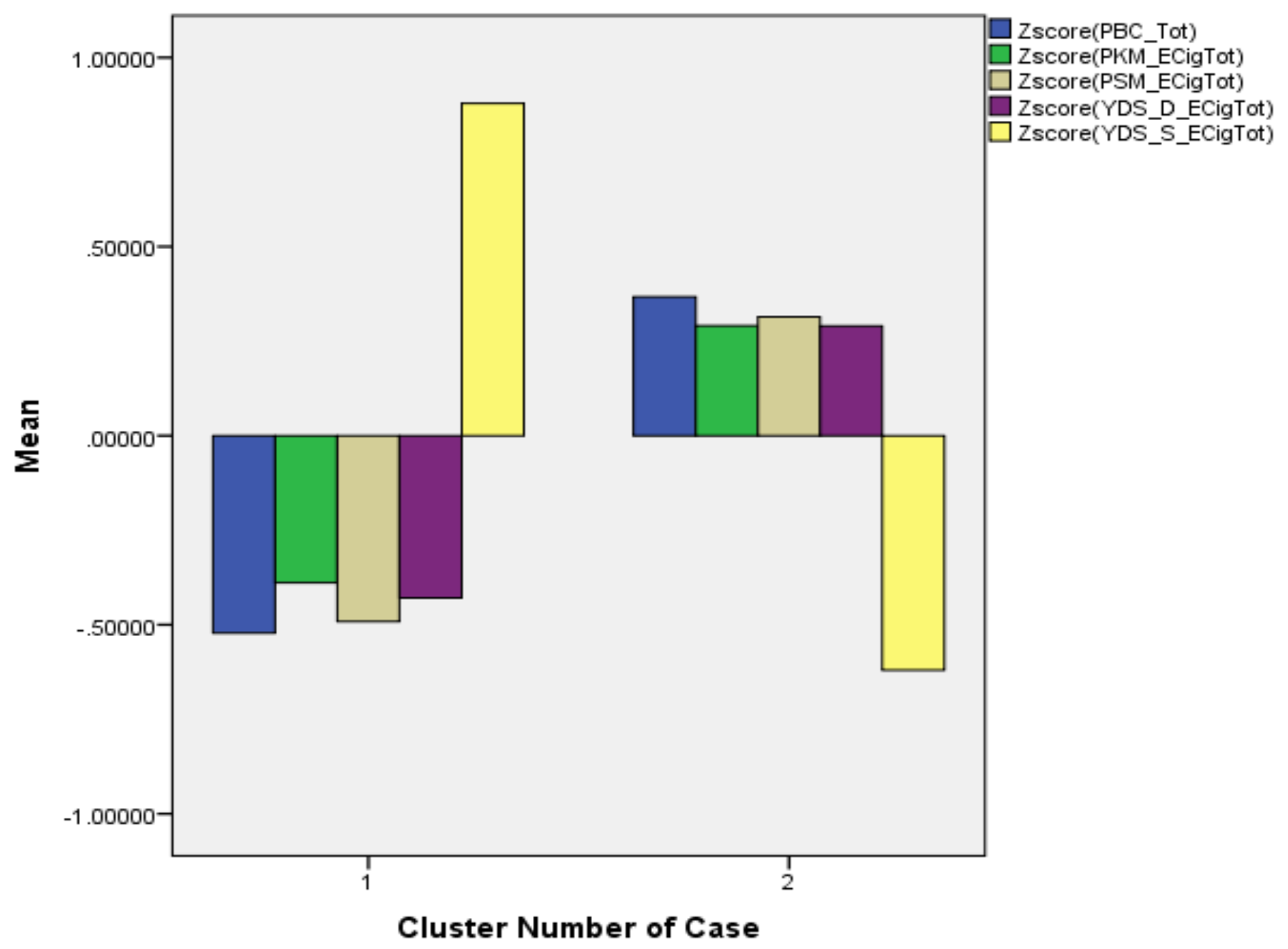

Figure 3. Final Cluster Solution. 